\title{
Stereo- and regioselective hydroboration of 1-exo-methylene pyranoses: discovery of aryltriazolylmethyl C-galactopyrano- sides as selective galectin-1 inhibitors
}

\author{
Alexander Dahlqvist ${ }^{1}$, Axel Furevi ${ }^{\ddagger 1}$, Niklas Warlin ${ }^{\ddagger 1}$, Hakon Leffler ${ }^{2}$ and Ulf J. Nilsson*1
}

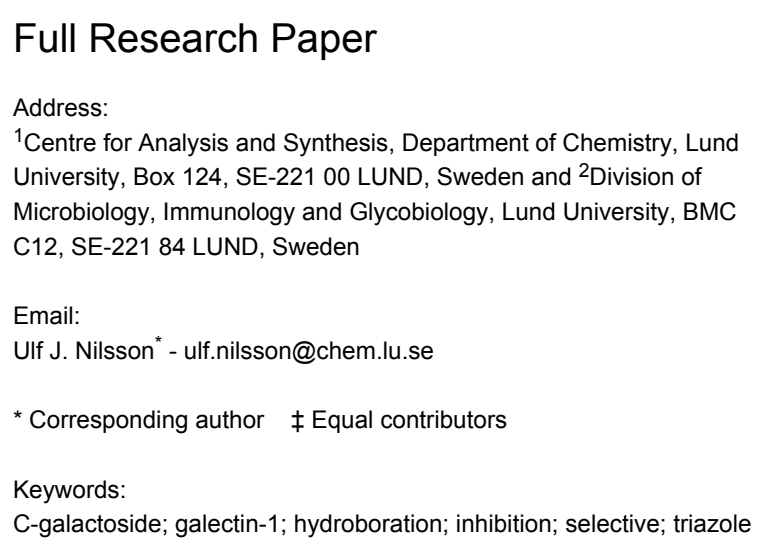

Beilstein J. Org. Chem. 2019, 15, 1046-1060. doi:10.3762/bjoc.15.102

Received: 07 February 2019

Accepted: 21 April 2019

Published: 07 May 2019

Associate Editor: S. Flitsch

(c) 2019 Dahlqvist et al.; licensee Beilstein-Institut. License and terms: see end of document.

\begin{abstract}
Galectins are carbohydrate recognition proteins that bind carbohydrates containing galactose and are involved in cell signaling and cellular interactions, involving them in several diseases. We present the synthesis of (aryltriazolyl)methyl galactopyranoside galectin inhibitors using a highly diastereoselective hydroboration of $\mathrm{C} 1$-exo-methylene pyranosides giving inhibitors with fourfold or better selectivity for galectin-1 over galectin-3, $-4 \mathrm{C}$ (C-terminal CRD), $-4 \mathrm{~N}$ (N-terminal CRD), -7, $-8 \mathrm{C},-8 \mathrm{~N},-9 \mathrm{C}$, and $-9 \mathrm{~N}$ and dissociation constants down to $170 \mu \mathrm{M}$.
\end{abstract}

\section{Introduction}

Galectins are defined by a typically about 130 amino acid carbohydrate recognition domain (CRD) that binds to carbohydrates with at least one $\beta$-galactose subunit within a binding pocket large enough to accommodate a tetrasaccharide sequence of larger glycans [1-3]. Some galectins contain one CRD and occur as monomers or dimers, including galectins -1 , $-2,-7,-10$ and -13 in humans. Others contain 2 different CRDs within the same peptide sequence and include galectins $-4,-8$, -9 and -12 . Galectin-3 contains one CRD and a long N-terminal Pro/Gly-rich intrinsically disordered sequence $[3,4]$. The two most studied galectins, galectin- 1 and -3 , are present in a wide variety of tissues. Galectin-3 is almost ubiquitously expressed while galectin-1 is mainly expressed by immune cells, muscle cells, kidney cells and neurons [2,3]. Galectin-1 has a marked preference for binding N-linked glycans, while galectin-3 binds both O-linked and N-linked glycans [5]. Galectins play many biological roles in the body and one important and well-understood function is the cross-linking of cell-surface glycoproteins through binding to $\mathrm{O}$ and $\mathrm{N}$-linked glycans on the cell surface. Surface proteins such as integrins [6,7], vascular endothelial growth factor receptor [8], and lysosome-associated membrane proteins [9] are known to be crosslinked by galectins, giving 
galectins a modulating role in cell adhesion, blood vessel growth and cellular uptake and breakdown, respectively. The association of galectins to cell signaling and adhesion gives them roles in several different pathological processes, such as pulmonary fibrosis $[6,10]$, pathological lymphangiogenesis [11], inflammation [12] and cancer [13], with galectin inhibitors demonstrated to attenuate such processes $[3,10,11,14]$. Experimental galectin inhibitors have often been developed with a close resemblance to natural disaccharide ligands, such as lactose and $N$-acetyllactosamine (lacNAc) [15] via thiodigalactosides [16-19], as adding a second monosaccharide unit to the anomeric position of the minimal D-galactose ligand allows for an additional affinity-enhancing hydrogen bond according to structural and affinity analyses [20,21]. A complementary strategy has been to, instead of a second saccharide unit, add non-natural structural elements to a monogalactoside scaffold, as such derivatives have been hypothesized to allow for tuning of galectin selectivities and to be designed to have improved pharmacokinetic properties over natural saccharide fragments. Early reports along this strategy involved C-galactosides that were shown to reach affinities approaching those of lactose and LacNAc for galectin-3 and also to have selectivity over other galectin-1 [22,23]. Later, combining non-natural thiophenyl aglycons with $\mathrm{C} 3$-triazole groups at $\mathrm{D}$-galactose led to the discovery of high affinity and selective galectin-3 inhibitors [24]. In this work, we present a synthesis pathway involving a diastereoselective hydroboration towards (aryltriazolyl)methyl galactopyranosyl derivatives and determined the viability of this as a scaffold for galectin inhibitors by screening a library of fourteen different products against galectins -1, -3, -4C (C-terminal CRD), $-4 \mathrm{~N}$ (N-terminal CRD), -7, $-8 \mathrm{C},-8 \mathrm{~N},-9 \mathrm{C}$, and $-9 \mathrm{~N}$.

\section{Results and Discussion Chemistry}

The synthesis starts from the known enol ethers 2,4 , and $\mathbf{6}$ prepared using published methods $[25,26]$. Hydroborations of enol ethers have been known to give good to excellent regio- and stereoselectivity and are thus a possible route to 2-deoxyhepuloses 3, 5 and 7 [27-30]. The hydroboration of enol ethers 2, 4, and $\mathbf{6}$ with borane dimethyl sulfide in THF, followed by oxidation using hydrogen peroxide and sodium hydroxide gave 2-deoxygalactoheptulose $\mathbf{3}$ and 2-deoxymannoheptulose $\mathbf{5}$ in good yields (89\% and 78\%) and with excellent diastereoselectivities (1:19 and 1:99 $\alpha: \beta$ ratio, respectively). Hydroboration of the glucose enol ether $\mathbf{6}$ afforded a mixture of both diastereomers ( $1: 2.3 \alpha: \beta$ ratio) in good yield ( $43 \% \beta$ and $18 \% \alpha$ isolated yields, respectively). Identification of the diastereomers was accomplished by NOESY experiments using deuterated pyridine as a shift reagent solvent. Other hydroboration reagents, such as 9-borabicyclo[3.3.1] nonane (9-BBN) or pinacolborane, resulted in no conversion of $\mathbf{2}$ and an almost complete recovery of starting material in repeated experiments, although 9-BBN is known to convert the gluco analog 6 to $\beta-7$ in high yield and with excellent stereoselectivity [31]. In none of the reaction conditions 1-methyl glycopyranoside side products were formed (Scheme 1).

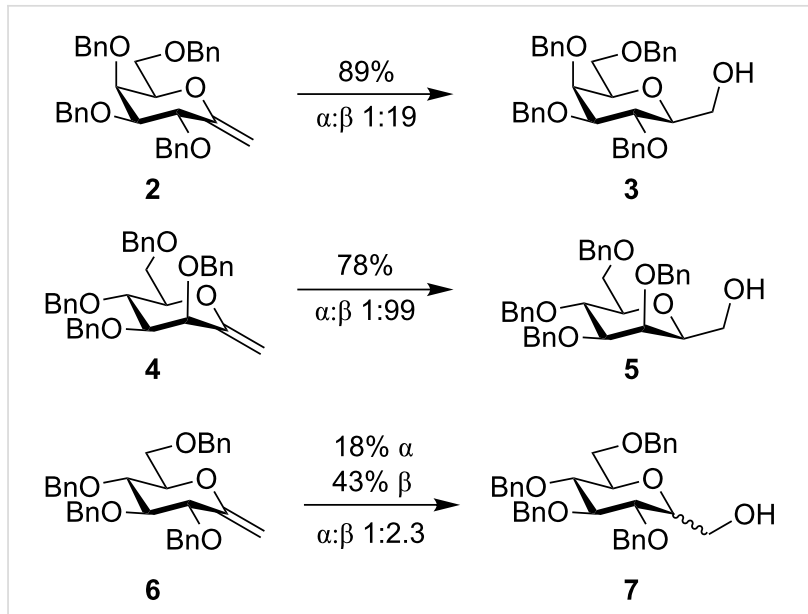

Scheme 1: Diastereoselective hydroboration of glycopyranosyl exomethylene enol ethers 2, 4, and 6: a) $\mathrm{BH}_{3}-\mathrm{DMS}$, THF, $0{ }^{\circ} \mathrm{C}, 2 \mathrm{~h}$; b) $\mathrm{H}_{2} \mathrm{O}_{2}, \mathrm{NaOH}, \mathrm{THF} /$ water, $0^{\circ} \mathrm{C}, 2 \mathrm{~h}$.

Continuing the synthesis towards (aryltriazolyl)methyl galactopyranosyl derivatives, the 2-deoxygalactoheptulose $\mathbf{3}$ was mesylated with mesyl chloride in pyridine at $0{ }^{\circ} \mathrm{C}$ to give 2-deoxy-1-mesylgalactoheptulose 8 (91\%), followed by a nucleophilic substitution reaction with sodium azide in dimethylformamide to give the azide 9 in good yield (90\%) [26]. The azide 9 was reacted with a panel of substituted ethynyl arenes to give (aryltriazolyl)methyl galactopyranosyls $\mathbf{1 0 a}-\mathbf{n}$ in fair to good yields (42-78\% yields) via a copper-catalyzed Huisgen cycloaddition [17,32]. The resulting (aryltriazolyl)methyl galactopyranosyls $\mathbf{1 0 a}-\mathbf{n}$ were debenzylated using palladium hydroxide on carbon in a 2:1 cyclohexene and ethanol mixture to give $\mathbf{1 a}-\mathbf{n}$ in yields varying from poor to good (10-87\% yields, Scheme 2). The transfer hydrogenation was selected as common hydrogenation using conditions with hydrogen gas and palladium on carbon lead to very low yields or no recovered product during the synthesis of $\mathbf{1 a}, \mathbf{b}$. Unfortunately, no arenes bearing halogen substituents other than fluorine could be prepared, as they were dehalogenated during the final debenzylation.

\section{Galectin binding}

Galectin-1, -3, -4C (C-terminal CRD), -4N (N-terminal CRD), $-7,-8 \mathrm{C},-8 \mathrm{~N},-9 \mathrm{C}$, and $-9 \mathrm{~N}$ affinities for (aryltriazolyl)methyl galactopyranosyls $\mathbf{1 a}-\mathbf{n}$ were determined in a competitive fluorescence polarization titration assay $[6,15-18,33]$. Compounds 


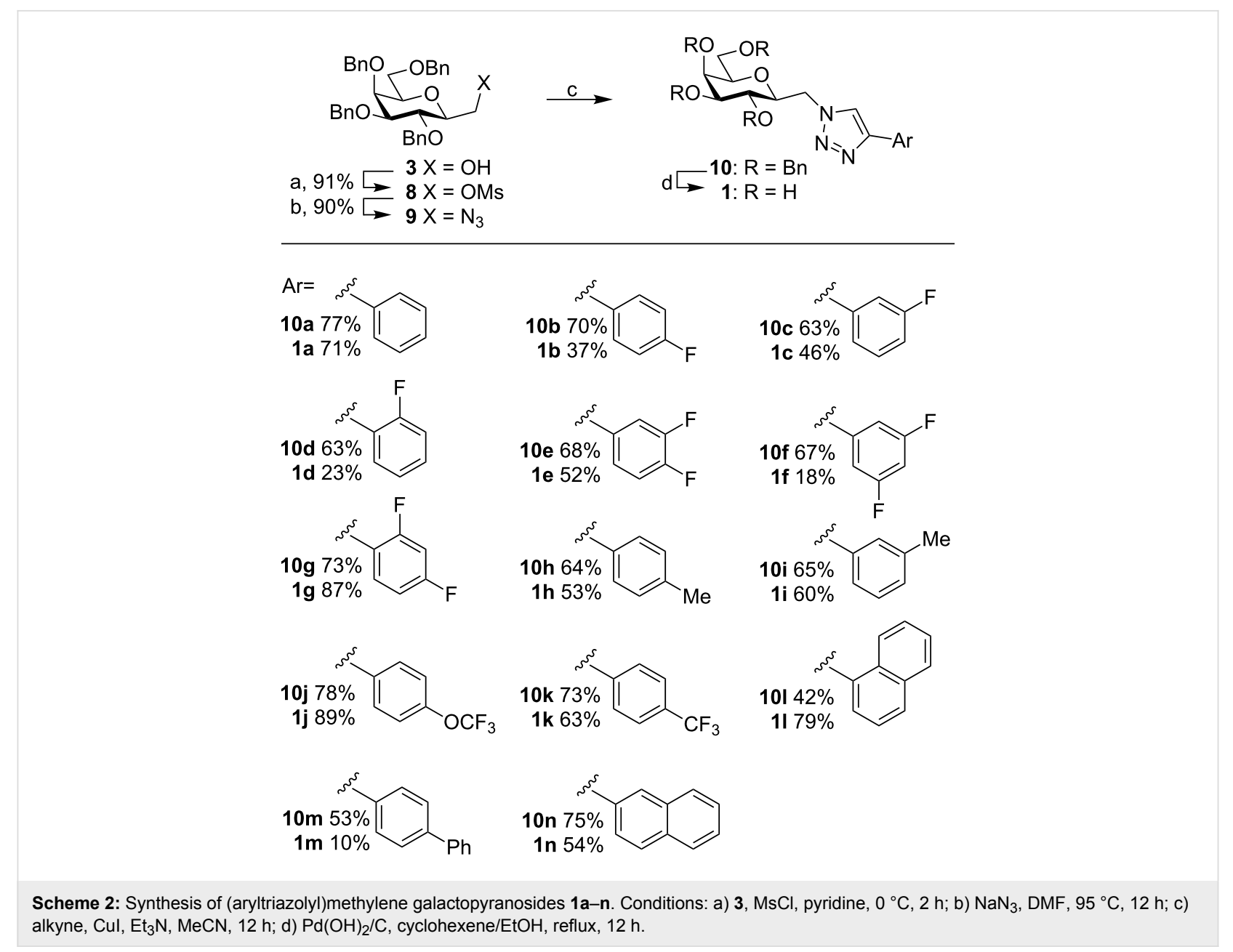

1a-n had millimolar or higher affinities for all galectins except for galectins-1 and -3. Generally, compounds based on the (aryltriazolyl)methyl galactopyranoside scaffold were selective for galectin-1, with the best ligand (4-fluorophenyltriazolyl)methyl galactopyranoside $\mathbf{1 b}$ having an affinity of $170 \pm 2 \mu \mathrm{M}$ and fourfold better than for galectin-3 (Table 1). The (4-(trifluoromethyl)phenyltriazolyl)methyl galactopyranoside $1 \mathrm{k}$ displayed a comparable affinity of $240 \pm 61 \mu \mathrm{M}$, but slightly lower selectivity over galectin-3. (1-Naphthyltriazolyl)methyl galactopyranoside $\mathbf{1 l}$ also displayed a good affinity of $180 \pm 20 \mu \mathrm{M}$ for galectin-1 with a threefold selectivity over galectin-3. Methyl substituents gave ligands $(\mathbf{1} \mathbf{h}, \mathbf{i})$ with poor galectin-1 affinity and undetectable galectin-3 binding, rendering them ineffective as galectin inhibitors. The contrast between the 4-methylphenyl $\mathbf{1 h}$ and the 4-trifluoromethylphenyl $1 \mathbf{k}$ is interesting, suggesting that the affinity of $\mathbf{1 k}$ may be explained by fluorine interaction(s) and/or solvation effects. Of particular interest is the different difluorinated aryls 1e-g, which show a reversed selectivity pattern. They display twofold preference for galectin-3 (1g), but their poor affinities limit their use as effective galectin- 3 inhibitors. Furthermore, the 3-fluoro and 2-fluoro derivatives $\mathbf{1 c}$ and $\mathbf{1 d}$, respectively also show a reversed galectin selectivity, but with only about twofold selectivity and poor affinity. The most potent galectin-1 inhibitor $\mathbf{1 b}$ has at least fiftyfold better affinity than the reference monosaccharide methyl $\beta$-D-galactoside (11) and a similar affinity as the reference disaccharide methyl $\beta$-lactoside (12). Hence, the 4-fluorophenyltriazol moiety of $\mathbf{1 b}$ efficiently replaces the galectin-1-interacting glucose unit in methyl $\beta$-lactoside (12) and at the same time induces a significantly better selectivity than that of methyl $\beta$-lactoside (12). Taken together, the 4-fluorophenyltriazole $\mathbf{1 b}$ represents the most potent mono-galactoside-derived galectin-1 inhibitor, albeit with an apparently lower selectivity than reported C-galactosides [22,23]. Monosaccharide derivatives with somewhat higher affinity for galectin-1 are known; dissociation constants down to $62 \mu \mathrm{M}$ and selectivity of 8 over galectin-3 [34]. However, these inhibitors are larger and carry double modifications with an anomeric thiophenyl aglycon combined with a heteroaryltriazole moiety at galactose $\mathrm{C} 3$ that both form affinity and selectivity-enhancing interactions with galectin-1. Unfortunately, attempts to combine the anomeric 4-fluorophenyltriazolyl- 
methyl moiety of compound $\mathbf{1 b}$ with such a galactose C3-thiazolyltriazole substituent reported to enhance affinity for galectin-1 [34] failed in our hands, why other additional substituents to combine with the 4-fluorophenyltriazolylmethyl moiety of compound $\mathbf{1 b}$ remain to be discovered.

\begin{tabular}{|c|c|c|c|}
\hline & \multicolumn{2}{|c|}{ Galectin- } & \multirow{2}{*}{$\begin{array}{l}\text { Selectivity } \\
\text { Galectin-1/3 }\end{array}$} \\
\hline & 1 & 3 & \\
\hline $1 a$ & $600 \pm 48$ & $870 \pm 37$ & 1.5 \\
\hline $1 b$ & $170 \pm 2$ & $710 \pm 36$ & 4.2 \\
\hline $1 c$ & $1200 \pm 120$ & $720 \pm 64$ & 0.6 \\
\hline $1 d$ & $390 \pm 38$ & $500 \pm 23$ & 1.3 \\
\hline $1 e$ & $860 \pm 150$ & $610 \pm 160$ & 0.7 \\
\hline $1 f$ & $1100 \pm 43$ & $790 \pm 48$ & 0.7 \\
\hline $1 \mathrm{~g}$ & $1100 \pm 16$ & $490 \pm 55$ & 0.4 \\
\hline $1 \mathrm{~h}$ & $1000 \pm 130$ & $>3000$ & $>3$ \\
\hline $1 \mathrm{i}$ & $990 \pm 23$ & $>3000$ & $>3$ \\
\hline $1 \mathrm{j}$ & $500 \pm 59$ & $700 \pm 52$ & 1.4 \\
\hline $1 k$ & $240 \pm 61$ & $830 \pm 38$ & 3.5 \\
\hline $1 I$ & $180 \pm 20$ & $470 \pm 95$ & 2.6 \\
\hline $1 \mathrm{~m}$ & $710 \pm 12$ & $1200 \pm 11$ & 1.7 \\
\hline $1 n$ & $1500 \pm 290$ & $1700 \pm 190$ & 1.1 \\
\hline 11 [35] & $>10000$ & 4400 & 0.4 \\
\hline 12 [35] & 190 & 220 & 1.2 \\
\hline
\end{tabular}

\section{Molecular modelling}

In order to gain understanding of the affinity-enhancing effects of the aryltriazolyl C-galactoside aglycons, we performed a $200 \mathrm{~ns}$ molecular dynamic simulation of $\mathbf{1 b}$ in the complex with galectin-1 and galectin-3. Starting conformations were selected with the galactopyranose of $\mathbf{1 b}$ positioned overlapping with the positions of the lactose or $\mathrm{N}$-acetyllactosamine galactopyranoses in galectin-1 (pdb id 1GZW) and galectin-3 (pdb id $1 \mathrm{KJL}$ ), respectively, and with the 4-fluorophenyltriazol ring protruding away from the protein. The simulations with $\mathbf{1 b}$ and galectin-1 converged toward a complex geometry in which the 4-fluorophenyltriazole extended along a shallow groove formed by Trp68-Gly69-Thr70-Glu71, while complex geometries in which the 1b 4-fluorophenyltriazole interacted with the His52 that is situated above the $\beta$-face of the bound galactopyranose ring were less populated (Figure 1). The preferred complex geometry with the 4-fluorophenyltriazole extending along the Trp68-Gly69-Thr70-Glu71 groove may, in addition to a more favorable steric complementarity, benefit from the electronpoor triazole hydrogen sampling positions close to the Glu71 carboxylate and the electron-rich triazole nitrogens sampling positions close to the rim of Trp68 side chain. This hypothesis may also explain the weaker affinity by the corresponding 2-fluorophenyltriazole analogue 1d, because in the favored complex geometry of $\mathbf{1 b}$ introduction of a 2-fluoro atom would lead to this atom being close to either the Glu71 carboxylate or the triazole N3 lone pair.

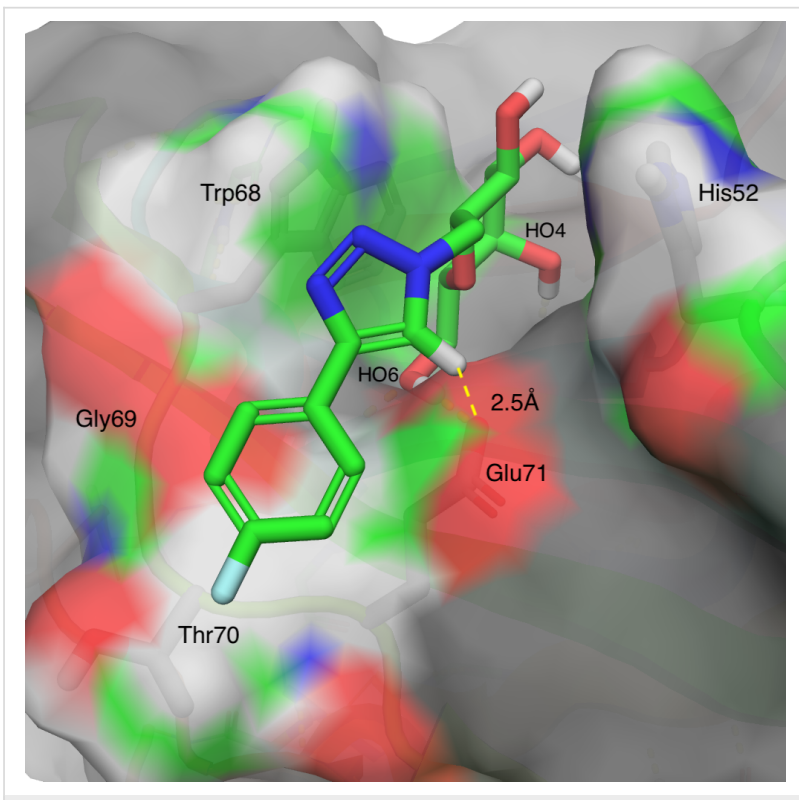

Figure 1: Galectin-1 in complex with $1 \mathrm{~b}$ derived by energy-minimizing a representative snapshot from a 200 ns molecular dynamic simulation. The distance between the triazole hydrogen and the Glu71 carboxylate is depicted with a yellow dashed line. The image was generated using PyMOL v1.7 (Schrodinger LLC).

MD simulations with $\mathbf{1 b}$ positioned in a similar manner in the complex with galectin-3 converged to a similar complex geometry with the 4-fluorophenyltriazole rings extending along a shallow, but somewhat wider groove formed by the corresponding galectin-3 side chains Trp181-Gly182-Arg183-Glu184, which may explain why several of the aryltriazoles 1 also possess enhanced affinity for galectin-3 as compared to the reference methyl galactoside (11). Although the binding groove interacting with the ligand 4-fluorophenyl moiety is somewhat wider in galectin-3, analyses of factors underlying the 4-fold galectin-1 selectivity remain inconclusive.

\section{Conclusion}

Hydroboration of 1-exo-methylene pyranosides $\mathbf{2}$ and $\mathbf{4}$ gives 3,4,5,7-tetra-O-benzyl-2-deoxy-D-galactoheptulose (3) and 3,4,5,7-tetra- $O$-benzyl-2-deoxy-D-mannoheptulose (5) in good yields and with excellent diastereoselectivities. This opens a quick, high-yielding route to (aryltriazolyl)methyl galactopyranosyls 1a-n, a majority of which are galectin-1 selective with dissociation constants down to $170 \pm 2 \mu \mathrm{M}$ (1b) and fourfold or better selectivity for galectin-1 over other galectins. This is comparable to or better than known C-galactoside based 
galectin-1 inhibitors with almost a factor of two [22,23]. Hence, one monosaccharide moiety, glucose $/ N$-acetylglucosamine of the common disaccharide ligands lactose $/ N$-acetyllactosamine has effectively been replaced with an aryltriazole motif, which is chemically wholly dissimilar and more selective. This opens a route towards galectin inhibitors with improved selectivities and potentially better pharmacokinetic properties than existing inhibitors based on lactose- and thiodigalactoside or other disaccharide core structures.

\section{Experimental General procedures}

Chemicals were obtained from Sigma-Aldrich unless otherwise stated and used without further purification, unless stated in the procedure. NMR spectra were collected on a Bruker Ultrashield Plus/Avance II $400 \mathrm{MHz}$ spectrometer. ${ }^{1} \mathrm{H}$ NMR spectra were recorded at $400 \mathrm{MHz}$ and ${ }^{13} \mathrm{C}$ NMR spectra at $100 \mathrm{MHz}$ with residual solvent signals as references. ${ }^{19} \mathrm{~F}$ NMR spectra were recorded at $376 \mathrm{MHz}$. Stereochemistry was assigned through NOESY using pyridine- $d_{5}$ as a shift reagent solvent. All final compounds were purified using preparative HPLC on an Agilent 1260 Infinity system with a SymmetryPrep C18 $5 \mu \mathrm{M} 19 \times 100 \mathrm{~mm}$ column using a gradient (water with $0.1 \%$ formic acid and acetonitrile); $0-20 \min 10-100 \%$ acetonitrile, 20-23 min 100\% acetonitrile. Monitoring and collection based on UV-vis absorbance at $210 \mathrm{~nm}$ and $254 \mathrm{~nm}$, respectively. Purity analysis was performed using UPLC-MS with UV-vis detection on a Waters Acquity UPLC + Waters XEVO-G2 system using a Waters Acquity CSH C18, $1.7 \mu \mathrm{m}$, $2.1 \times 100 \mathrm{~mm}$ column. Samples were run using a gradient with water $(0.1 \%$ formic acid) and acetonitrile using a flow rate of $0.50 \mathrm{~mL} / \mathrm{min}$ and a column temperature $60{ }^{\circ} \mathrm{C}$. Gradient parameters: $0-0.7 \mathrm{~min}$ : $40 \%$ acetonitrile, $0.7-10.0 \mathrm{~min}$ : $40-99 \%$ acetonitrile, $10.0-11.0 \mathrm{~min} 99 \%$ acetonitrile, $11.0-11.1 \mathrm{~min}$ $99-40 \%$ acetonitrile, $11.1-13 \mathrm{~min} 40 \%$ acetonitrile, 3 or $6 \mu \mathrm{L}$ injection, detection 190-300 nm. MS parameters: Cap voltage $3.0 \mathrm{kV}$, cone voltage $40 \mathrm{kV}$, Ext 4, source temperature $120^{\circ} \mathrm{C}$, desolvation temperature $500{ }^{\circ} \mathrm{C}$, cone gas 50 , desolvation gas 800, centroid resolution mode, $\mathrm{m} / \mathrm{z}$ interval 50-1200, lockspray. Calibration: Leu-enkephalin $\mathrm{m} / z$ 556.2771, $0.25 \mathrm{~s}$ every $30 \mathrm{~s}$, average 3 . For optical rotation measurements, samples were dissolved in an appropriate solvent to a concentration of $2-10 \mathrm{mg} / \mathrm{mL}$. Polarimetry was performed on a PerkinElmer Model 341 Polarimeter using a sodium lamp and measuring at $589 \mathrm{nM}$ with a $90 \mathrm{~mm}$ long $1 \mathrm{~mL}$ cell at $20{ }^{\circ} \mathrm{C}$. For infrared spectroscopy, samples were pelleted with potassium bromide and analyzed on a Shimadzu FTIR-84005.

1,2-Dideoxy-1-(4-phenyl-1H-1,2,3-triazol-1-yl)- $\beta$-D-galactoheptulose (1a): Compound 10a (42 mg, $0.062 \mathrm{mmol}$ ) was dissolved in cyclohexene/ethanol 2:1 (1.5 mL), palladium(II) hydroxide on charcoal (17 mg, $20 \mathrm{wt} \%$ ) was added and the mixture refluxed overnight at $80{ }^{\circ} \mathrm{C}$. The reaction mixture was diluted with methanol $(15 \mathrm{~mL})$, filtered through Celite, evaporated, purified by column chromatography (5:1, dichloromethane/methanol), and then preparative HPLC (gradient from $10 \%$ acetonitrile $/ 90 \%$ water with $0.1 \%$ formic acid to $100 \%$ acetonitrile over $20 \mathrm{~min}$, followed by $3 \mathrm{~min}$ of $100 \%$ acetonitrile) to give $\mathbf{1 a}(14 \mathrm{mg}, 71 \%)$ as a white powder. $[\alpha]_{\mathrm{D}}{ }^{20} 24(c$ 0.6, methanol); ${ }^{1} \mathrm{H}$ NMR (400 MHz, $\left.\mathrm{CD}_{3} \mathrm{OD}\right) \delta 8.42(\mathrm{~s}, 1 \mathrm{H})$, 7.86-7.81 (m, 2H), 7.48-7.42 (m, 2H), 7.38-7.33 (m, 1H), $4.98-4.95(\mathrm{~m}, 1 \mathrm{H}), 4.57$ (dd, $J=14.4 \mathrm{~Hz}, 7.5 \mathrm{~Hz}, 1 \mathrm{H}, \mathrm{H} 1)$, $3.91-3.88$ (m, 1H, H5), 3.78 (dd, $J=10.8 \mathrm{~Hz}, 7.35 \mathrm{~Hz}, 1 \mathrm{H}$, $\mathrm{H} 7), 3.70$ (dd, $J=12.1 \mathrm{~Hz}, 4.8 \mathrm{~Hz}, 1 \mathrm{H}, \mathrm{H} 7), 3.60-3.48$ (m, $4 \mathrm{H}) ;{ }^{13} \mathrm{C} \mathrm{NMR}\left(100 \mathrm{MHz}, \mathrm{CD}_{3} \mathrm{OD}\right) \delta 128.5,127.9,125.3$, $122.3,78.9,78.7,74.7,69.5,68.4,61.5,51.5$; HRMS $(\mathrm{m} / \mathrm{z})$ : $[\mathrm{M}+\mathrm{H}]^{+}$calcd for 322.1403 ; found, 322.1402 ; purity by HPLC, UV-vis detection: $98.4 \%$.

1,2-Dideoxy-1-[4-(4-fluorophenyl)-1 H-1,2,3-triazol-1-yl]- $\beta$ D-galactoheptulose (1b): Compound 10b (50 mg, $0.147 \mathrm{mmol}$ ) was dissolved in cyclohexene/ethanol 2:1 (3 mL), palladium(II) hydroxide on charcoal (40 mg, $20 \mathrm{wt} \%$ ) was added, and the mixture refluxed overnight at $80{ }^{\circ} \mathrm{C}$. The reaction mixture was diluted with methanol $(15 \mathrm{~mL})$, filtered through Celite, evaporated, purified by column chromatography (dichloromethane/ methanol 5:1), and then preparative HPLC (gradient from 10\% acetonitrile $/ 90 \%$ water with $0.1 \%$ formic acid to $100 \%$ acetonitrile over $20 \mathrm{~min}$, followed by $3 \mathrm{~min}$ of $100 \%$ acetonitrile) to give $\mathbf{1 b}(9 \mathrm{mg}, 37 \%)$ as a white powder. $[\alpha]_{\mathrm{D}}{ }^{20} 17(c 0.7$, $\left.\mathrm{CD}_{3} \mathrm{OD}\right) ;{ }^{1} \mathrm{H}$ NMR (400 MHz, CD $\left.{ }_{3} \mathrm{OD}\right) \delta 8.43(\mathrm{~s}, 1 \mathrm{H})$, $7.88-7.82(\mathrm{~m}, 2 \mathrm{H}), 7.24-7.16(\mathrm{~m}, 2 \mathrm{H}), 4.95$ (dd, $J=14.36 \mathrm{~Hz}$, $2.0 \mathrm{~Hz}, 1 \mathrm{H}, \mathrm{H} 1), 4.58$ (dd, $J=13.6,7.2 \mathrm{~Hz}, \mathrm{H} 1), 3.89$ (dd, $J=$ $2.9 \mathrm{~Hz}, 0.9 \mathrm{~Hz}, 1 \mathrm{H}, \mathrm{H} 5), 3.78$ (dd, $J=11.4 \mathrm{~Hz}, 7.2 \mathrm{~Hz}, 1 \mathrm{H}$, H7), 3.69 (dd, $J=11.5 \mathrm{~Hz}, 4.6 \mathrm{~Hz}, 1 \mathrm{H}, \mathrm{H} 7), 3.60-3.49$ (m, $4 \mathrm{H}) ;{ }^{13} \mathrm{C} \mathrm{NMR}\left(100 \mathrm{MHz}, \mathrm{CD}_{3} \mathrm{OD}\right) \delta 161.6,146.2,127.4$, 127.3, 126.6, 122.4, 115.5, 115.3, 79.0, 78.6, 74.7, 69.4, 68.4, $61.5,51.6 ;{ }^{19} \mathrm{~F}$ NMR (376 MHz, $\left.\mathrm{CD}_{3} \mathrm{OD}\right) \delta-115.54$; HRMS $(m / z):[\mathrm{M}+\mathrm{H}]^{+}$calcd for 340.1306 ; found, 340.1309 ; purity by HPLC, UV-vis detection: $95.6 \%$.

\section{1,2-Dideoxy-1-[4-(3-fluorophenyl)-1 H-1,2,3-triazol-1-yl]- $\beta$ -} D-galactoheptulose (1c): Compound 10c (71 mg, $0.102 \mathrm{mmol}$ ) was dissolved in cyclohexene/ethanol 2:1 (4.5 mL), $27 \mathrm{mg}$ of $20 \mathrm{wt} \%$ palladium(II) hydroxide on charcoal was added, and the mixture refluxed overnight at $80{ }^{\circ} \mathrm{C}$. The reaction mixture was diluted with methanol $(15 \mathrm{~mL})$, filtered through Celite, evaporated, and purified by column chromatography (dichloromethane/methanol 5:1), and then preparative HPLC (gradient from $10 \%$ acetonitrile $/ 90 \%$ water with $0.1 \%$ formic acid to $100 \%$ acetonitrile over $20 \mathrm{~min}$, followed by $3 \mathrm{~min}$ of $100 \%$ acetonitrile) to give $1 \mathrm{c}(16 \mathrm{mg}, 46 \%)$ as a white powder. $[\alpha]_{\mathrm{D}}{ }^{20}$ 
19 (c 0.6, $\left.\mathrm{CD}_{3} \mathrm{OD}\right) ;{ }^{1} \mathrm{H} \mathrm{NMR}\left(400 \mathrm{MHz}, \mathrm{CD}_{3} \mathrm{OD}\right) \delta 8.47$ (s, $1 \mathrm{H}), 7.68-7.64(\mathrm{~m}, 1 \mathrm{H}), 7.62-7.57(\mathrm{~m}, 1 \mathrm{H}), 7.50-7.43(\mathrm{~m}, 1 \mathrm{H})$, $7.12-7.06(\mathrm{~m}, 1 \mathrm{H}), 4.95$ (dd, $J=14.4 \mathrm{~Hz}, 1.9 \mathrm{~Hz}, 1 \mathrm{H}, \mathrm{H1}), 4.58$ (dd, $J=14.2 \mathrm{~Hz}, 7.7 \mathrm{~Hz}, 1 \mathrm{H}, \mathrm{H1}$ ), 3.90 (dd, $J=2.9 \mathrm{~Hz}, 0.9 \mathrm{~Hz}$, 1H, H5), 3.79 (dd, $J=11.2 \mathrm{~Hz}, 6.9 \mathrm{~Hz}, 1 \mathrm{H}, \mathrm{H} 7), 3.70$ (dd, $J=$ $11.6 \mathrm{~Hz}, 4.71 \mathrm{~Hz}, 1 \mathrm{H}, \mathrm{H} 7), 3.60-3.48(\mathrm{~m}, 4 \mathrm{H}) ;{ }^{13} \mathrm{C} \mathrm{NMR}$ $\left(100 \mathrm{MHz}, \mathrm{CD}_{3} \mathrm{OD}\right) \delta 164.5,146.2,132.9,130.5,122.9,121.1$, $114.4,111.9,78.9,78.7,74.769 .4,68.4,61.5,51.5 ;{ }^{19} \mathrm{~F}$ NMR (376 MHz, $\left.\mathrm{CD}_{3} \mathrm{OD}\right) \delta-114.83$; HRMS $(\mathrm{m} / \mathrm{z})$ : $[\mathrm{M}+\mathrm{H}]^{+}$calcd for 340.1314 ; found, 340.1309 ; purity by HPLC, UV-vis detection: $99.6 \%$.

1,2-Dideoxy-1-[4-(2-fluorophenyl)-1H-1,2,3-triazol-1-yl]- $\beta$ D-galactoheptulose (1d): Compound 10d (66 mg, $0.095 \mathrm{mmol}$ ) was dissolved in cyclohexene/ethanol 2:1 (4.5 mL), palladium(II) hydroxide on charcoal (25 mg, $20 \mathrm{wt} \%$ ) was added, and the mixture refluxed overnight at $80{ }^{\circ} \mathrm{C}$. The reaction mixture was diluted with methanol $(15 \mathrm{~mL})$, filtered through Celite, evaporated, purified by column chromatography (dichloromethane/methanol 5:1), and then preparative HPLC (gradient from $10 \%$ acetonitrile/ $90 \%$ water with $0.1 \%$ formic acid to $100 \%$ acetonitrile over $20 \mathrm{~min}$, followed by $3 \mathrm{~min}$ of $100 \%$ acetonitrile) to give $\mathbf{1 d}(8 \mathrm{mg}, 23 \%)$ as a white powder. $[\alpha]_{\mathrm{D}}{ }^{20} 27$ (c $\left.0.5, \mathrm{CD}_{3} \mathrm{OD}\right) ;{ }^{1} \mathrm{H} \mathrm{NMR}(400 \mathrm{MHz}$, $\left.\mathrm{CD}_{3} \mathrm{OD}\right) \delta 8.41(\mathrm{~d}, J=3.74 \mathrm{~Hz}, 1 \mathrm{H}), 8.11(\mathrm{td}, J=7.6 \mathrm{~Hz}$, $1.9 \mathrm{~Hz}, 1 \mathrm{H}), 7.43-7.37(\mathrm{~m}, 1 \mathrm{H}), 7.30(\mathrm{td}, J=7.6 \mathrm{~Hz}, 1.3 \mathrm{~Hz}$, 1H), 7.24 (ddd, $J=11.4 \mathrm{~Hz}, 8.3 \mathrm{~Hz}, 1.1 \mathrm{~Hz}, 1 \mathrm{H}), 4.97$ (dd, $J=$ $14.4 \mathrm{~Hz}, 2.1 \mathrm{~Hz}, 1 \mathrm{H}, \mathrm{H} 1), 4.60$ (dd, $J=13.9 \mathrm{~Hz}, 7.6 \mathrm{~Hz}, 1 \mathrm{H}$, H1), 3.92-3.89 (m, 1H), $3.75(J=11.3 \mathrm{~Hz}, 6.7 \mathrm{~Hz}, 1 \mathrm{H}, \mathrm{H} 7)$, $3.70(\mathrm{dd}, J=11.3 \mathrm{~Hz}, 5.1 \mathrm{~Hz}, 1 \mathrm{H}, \mathrm{H} 7), 3.62-3.49$ (m, 4H); ${ }^{13} \mathrm{C}$ NMR $\left(100 \mathrm{MHz}, \mathrm{CD}_{3} \mathrm{OD}\right) \delta 158.0,140.7,129.5,129.4$, $127.3,127.3,124.9,124.8,124.38,124.35,118.4,115.6,115.4$, $78.8,78.7,74.7,69.3,68.4,61.2,51.4 ;{ }^{19} \mathrm{~F} \mathrm{NMR}(376 \mathrm{MHz}$, $\left.\mathrm{CD}_{3} \mathrm{OD}\right) \delta-116.16$; $\operatorname{HRMS}(\mathrm{m} / \mathrm{z}):[\mathrm{M}+\mathrm{H}]^{+}$calcd for 340.1304; found, 340.1309; purity by HPLC, UV-vis detection: $98.5 \%$.

1,2-Dideoxy-1-[4-(3,4-difluorophenyl)-1H-1,2,3-triazol-1-yl]B-D-galactoheptulose (1e): Compound 10e (66 mg, $0.092 \mathrm{mmol})$ was dissolved in cyclohexene/ethanol 2:1 (4.5 $\mathrm{mL})$, palladium(II) hydroxide on charcoal $(24 \mathrm{mg}$, $20 \mathrm{wt} \%$ ) was added, and the mixture refluxed overnight at $80{ }^{\circ} \mathrm{C}$. The reaction mixture was diluted with methanol $(15 \mathrm{~mL})$, filtered through Celite, evaporated, purified by column chromatography (dichloromethane/methanol 5:1), and then preparative HPLC (gradient from 10\% acetonitrile/90\% water with $0.1 \%$ formic acid to $100 \%$ acetonitrile over $20 \mathrm{~min}$, followed by $3 \mathrm{~min}$ of $100 \%$ acetonitrile) to give $1 \mathrm{e}(17 \mathrm{mg}, 52 \%)$ as a white powder. $[\alpha]_{\mathrm{D}}{ }^{20} 16\left(c 0.8, \mathrm{CD}_{3} \mathrm{OD}\right) ;{ }^{1} \mathrm{H} \mathrm{NMR}$ $\left(400 \mathrm{MHz}, \mathrm{CD}_{3} \mathrm{OD}\right) \delta 8.44(\mathrm{~s}, 1 \mathrm{H}), 7.76(\mathrm{ddd}, J=11.7 \mathrm{~Hz}$, $7.8 \mathrm{~Hz}, 2.2 \mathrm{~Hz}, 1 \mathrm{H}), 7.67-7.62(\mathrm{~m}, 1 \mathrm{H}), 7.39-7.31(\mathrm{~m}, 1 \mathrm{H})$, $4.94(\mathrm{dd}, J=14.3 \mathrm{~Hz}, 1.9 \mathrm{~Hz}, 1 \mathrm{H}, \mathrm{H1}), 4.57$ (dd, $J=14.5 \mathrm{~Hz}$, $7.3 \mathrm{~Hz}, 1 \mathrm{H}, \mathrm{H} 1), 3.89$ (dd, $J=2.9 \mathrm{~Hz}, 1.1 \mathrm{~Hz}, 1 \mathrm{H}, \mathrm{H} 5), 3.78$ $(\mathrm{dd}, J=11.3 \mathrm{~Hz}, 7.4 \mathrm{~Hz}, 1 \mathrm{H}, \mathrm{H} 7), 3.70(\mathrm{dd}, J=11.6 \mathrm{~Hz}$, $4.7 \mathrm{~Hz}, 1 \mathrm{H}, \mathrm{H} 7), 3.59-3.49$ (m, 4H); ${ }^{13} \mathrm{C}$ NMR (100 MHz, $\left.\mathrm{CD}_{3} \mathrm{OD}\right) \delta 163.6,157.1,151.6,151.1,145.4,128.1,122.7$, $121.9,121.81,121.79,121.75,117.6,117.5,114.3,114.1,79.0$, $78.7,74.7,69.4,68.4,61.5,51.5 ;{ }^{19} \mathrm{~F}$ NMR $(376 \mathrm{MHz}$, $\left.\mathrm{CD}_{3} \mathrm{OD}\right) \delta-139.97,-140.03,-141.26,-141.31$; HRMS $(\mathrm{m} / \mathrm{z})$ : $[\mathrm{M}+\mathrm{H}]^{+}$calcd for 358.1212 ; found, 358.1215 ; purity by HPLC, UV-vis detection: $98.2 \%$.

1,2-Dideoxy-1-[4-(3,5-difluorophenyl)-1H-1,2,3-triazol-1-yl]B-D-galactoheptulose (1f): Compound $10 f(81 \mathrm{mg}$, $0.113 \mathrm{mmol})$ was dissolved in cyclohexene/ethanol 2:1 $(6 \mathrm{~mL})$ with 2 drops of acetic acid, palladium(II) hydroxide on charcoal (30 mg, $20 \mathrm{wt} \%$ ) was added and the mixture refluxed overnight at $80{ }^{\circ} \mathrm{C}$. The reaction mixture was diluted with $15 \mathrm{~mL}$ methanol, filtered through Celite, evaporated, purified by column chromatography (dichloromethane/methanol 5:1), and then preparative HPLC (gradient from 10\% acetonitrile/ $90 \%$ water with $0.1 \%$ formic acid to $100 \%$ acetonitrile over $20 \mathrm{~min}$, followed by $3 \mathrm{~min}$ of $100 \%$ acetonitrile) to give $\mathbf{1 f}$ ( $7 \mathrm{mg}, 18 \%)$ as a white powder. $[\alpha]_{\mathrm{D}}{ }^{20} 22\left(c 0.8, \mathrm{CD}_{3} \mathrm{OD}\right)$; ${ }^{1} \mathrm{H}$ NMR (400 MHz, CD $\left.{ }_{3} \mathrm{OD}\right) \delta 8.51(\mathrm{~s}, 1 \mathrm{H}), 7.51-7.44(\mathrm{~m}$, 2H), 6.98-6.91 (tt, $J=9.1 \mathrm{~Hz}, 2.3 \mathrm{~Hz}, 1 \mathrm{H}$, phenyl H4), 4.95 $(\mathrm{dd}, J=14.4 \mathrm{~Hz}, 2.0 \mathrm{~Hz}, 1 \mathrm{H}, \mathrm{H1}), 4.57$ (dd, $J=14.2 \mathrm{~Hz}$, $7.5 \mathrm{~Hz}, 1 \mathrm{H}, \mathrm{H} 1), 3.89$ (dd, $J=2.7 \mathrm{~Hz}, 1.2 \mathrm{~Hz}, 1 \mathrm{H}, \mathrm{H} 5), 3.79$ $(\mathrm{dd}, J=11.2 \mathrm{~Hz}, 7.3 \mathrm{~Hz}, 1 \mathrm{H}, \mathrm{H} 7), 3.70(\mathrm{dd}, J=11.3 \mathrm{~Hz}$, $4.7 \mathrm{~Hz}, 1 \mathrm{H}, \mathrm{H} 7), 3.59-3.47$ (m, 4H); ${ }^{13} \mathrm{C}$ NMR (100 MHz, $\left.\mathrm{CD}_{3} \mathrm{OD}\right) \delta 164.9,162.3,145.2,123.4,108.1,107.8,102.8$, 102.6, 102.0, 79.0, 78.6, 74.7, 69.4, 68.4, 61.5, 51.5; ${ }^{19} \mathrm{~F} \mathrm{NMR}$ (376 MHz, $\left.\mathrm{CD}_{3} \mathrm{OD}\right) \delta-111.27$; HRMS $(\mathrm{m} / \mathrm{z}):[\mathrm{M}+\mathrm{H}]^{+}$calcd for 358.1219 ; found, 358.1215 ; purity by HPLC, UV-vis detection: $99.6 \%$.

1,2-Dideoxy-1-[4-(2,4-difluorophenyl)-1H-1,2,3-triazol-1-yl]B-D-galactoheptulose (1g): Compound 10g (88 mg, $0.123 \mathrm{mmol})$ was dissolved in cyclohexene/ethanol 2:1 (6 mL), palladium(II) hydroxide on charcoal (69 mg, $20 \mathrm{wt} \%$ ) was added and the mixture refluxed overnight at $80{ }^{\circ} \mathrm{C}$. The reaction mixture was diluted with $15 \mathrm{~mL}$ methanol, filtered through Celite, evaporated, purified by column chromatography (dichloromethane/methanol 5:1), and then preparative HPLC (gradient from $10 \%$ acetonitrile $/ 90 \%$ water with $0.1 \%$ formic acid to $100 \%$ acetonitrile over $20 \mathrm{~min}$, followed by $3 \mathrm{~min}$ of $100 \%$ acetonitrile) to give $\mathbf{1 g}(40 \mathrm{mg}, 87 \%)$ as a clear solid. $[\alpha]_{\mathrm{D}}{ }^{20} 7$ (c 0.7, methanol); ${ }^{1} \mathrm{H}$ NMR (400 MHz, CD $\left.3 \mathrm{OD}\right) \delta 8.36$ $(\mathrm{d}, J=3.6 \mathrm{~Hz}, 1 \mathrm{H}), 8.14-8.07(\mathrm{~m}, 1 \mathrm{H}), 7.13-7.05(\mathrm{~m}, 2 \mathrm{H}), 4.95$ $(\mathrm{dd}, J=14.2 \mathrm{~Hz}, 2.0 \mathrm{~Hz}, 1 \mathrm{H}, \mathrm{H} 1), 4.60(\mathrm{dd}, J=14.2 \mathrm{~Hz}$, $7.6 \mathrm{~Hz}, 1 \mathrm{H}, \mathrm{H1}), 3.91(\mathrm{dd}, J=2.7 \mathrm{~Hz}, 1.0 \mathrm{~Hz}, 1 \mathrm{H}, \mathrm{H} 5)$, $3.77-3.67(\mathrm{~m}, 2 \mathrm{H}), 3.61-3.48(\mathrm{~m}, 4 \mathrm{H})$; ${ }^{13} \mathrm{C} \mathrm{NMR}(100 \mathrm{MHz}$, 
$\left.\mathrm{CD}_{3} \mathrm{OD}\right) \delta 163.6,163.5,161.6,161.5,160.3,160.2,158.3$, $158.2,139.91,139.89,128.5,128.44,128.40,128.36,124.5$, $124.4,115.0,114.9,114.84,114.81,111.58,111.55,111.40$, 111.37, 103.9, 103.7, 103.5, 78.7, 78.6, 74.6, 70.6, 69.2, 68.3, $61.2,60.7,51.4 ;{ }^{19} \mathrm{~F}$ NMR $\left(376 \mathrm{MHz}, \mathrm{CD}_{3} \mathrm{OD}\right) \delta-111.90$, -112.17 ; HRMS $(\mathrm{m} / \mathrm{z}):[\mathrm{M}+\mathrm{H}]^{+}$calcd for 358.1211 ; found, 358.1215 calculated. Purity by HPLC, UV-vis detection: $96.6 \%$.

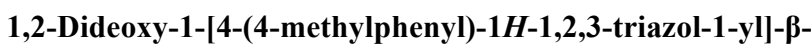
D-galactoheptulose (1h): Compound 10h (71 mg, $0.102 \mathrm{mmol})$ was dissolved in cyclohexene/ethanol $2: 1(4.5 \mathrm{~mL})$, palladium(II) hydroxide on charcoal (27 mg, $20 \mathrm{wt} \%$ ) was added, and the mixture refluxed overnight at $80^{\circ} \mathrm{C}$. The reaction mixture was diluted with methanol $(15 \mathrm{~mL})$, filtered through Celite, evaporated, purified by column chromatography (dichloromethane/methanol 5:1), and then preparative HPLC (gradient from 10\% acetonitrile/90\% water with $0.1 \%$ formic acid to $100 \%$ acetonitrile over $20 \mathrm{~min}$, followed by $3 \mathrm{~min}$ of $100 \%$ acetonitrile) to give $\mathbf{1 h}(18 \mathrm{mg}, 53 \%)$ as a white powder. $[\alpha]_{\mathrm{D}}{ }^{20} 19\left(c 0.9, \mathrm{CD}_{3} \mathrm{OD}\right)$; ${ }^{1} \mathrm{H}$ NMR $(400 \mathrm{MHz}$, $\left.\mathrm{CD}_{3} \mathrm{OD}\right) \delta 8.37(\mathrm{~s}, 1 \mathrm{H}), 7.74-7.69(\mathrm{~m}, 2 \mathrm{H}), 7.29-7.25(\mathrm{~m}, 2 \mathrm{H})$, $4.94(\mathrm{dd}, J=14.2 \mathrm{~Hz}, 1.8 \mathrm{~Hz}, 1 \mathrm{H}, \mathrm{H1}), 4.56(\mathrm{dd}, J=14.1 \mathrm{~Hz}$, $7.4 \mathrm{~Hz}, 1 \mathrm{H}, \mathrm{H1}$ ), 3.91-3.88 (m, 1H, H5), 3.78 (dd, $J=10.8 \mathrm{~Hz}$, $7.3 \mathrm{~Hz}, 1 \mathrm{H}, \mathrm{H} 7), 3.70$ (dd, $J=11.4 \mathrm{~Hz}, 4.8 \mathrm{~Hz}, 1 \mathrm{H}, \mathrm{H} 7)$, 3.60-3.48 (m, 4H), 2.39 (s, 3H); ${ }^{13} \mathrm{C}$ NMR (100 MHz, $\left.\mathrm{CD}_{3} \mathrm{OD}\right)$ $\delta 147.4,137.9,129.1,127.6,125.3,121.9,78.9,78.8,74.7$, 69.4, 68.4, 61.5, 51.4, 19.9; HRMS $(\mathrm{m} / \mathrm{z}):[\mathrm{M}+\mathrm{H}]^{+}$calcd for 336.1558 ; found, 336.1559 ; purity by HPLC, UV-vis detection: $99.6 \%$.

1,2-Dideoxy-1-[4-(3-methylphenyl)-1H-1,2,3-triazol-1-yl]- $\beta$ D-galactoheptulose (1i): Compound 10i (71 mg, $0.102 \mathrm{mmol})$ was dissolved in cyclohexene/ethanol 2:1 (4.5 mL), palladium(II) hydroxide on charcoal (27 mg, $20 \mathrm{wt} \%$ ) was added, and the mixture refluxed overnight at $80^{\circ} \mathrm{C}$. The reaction mixture was diluted with methanol $(15 \mathrm{~mL})$, filtered through Celite, evaporated, purified by column chromatography (dichloromethane/methanol 5:1), and then preparative HPLC (gradient from 10\% acetonitrile/90\% water with $0.1 \%$ formic acid to $100 \%$ acetonitrile over $20 \mathrm{~min}$, followed by $3 \mathrm{~min}$ of $100 \%$ acetonitrile) to give $\mathbf{1 i}(20 \mathrm{mg}, 60 \%)$ as a white powder. $[\alpha]_{\mathrm{D}}{ }^{20} 16$ (c 1, CD $\left.\mathrm{CD}_{3} \mathrm{OD}\right) ;{ }^{1} \mathrm{H}$ NMR $(400 \mathrm{MHz}$, $\left.\mathrm{CD}_{3} \mathrm{OD}\right) \delta 8.40(\mathrm{~s}, 1 \mathrm{H}), 7.66(\mathrm{~s}, 1 \mathrm{H}), 7.62(\mathrm{~d}, J=7.8 \mathrm{~Hz}, 1 \mathrm{H})$, $7.32(\mathrm{t}, J=7.6 \mathrm{~Hz}, 1 \mathrm{H}), 7.18(\mathrm{~d}, J=7.6 \mathrm{~Hz}, 1 \mathrm{H}), 4.94(\mathrm{dd}, J=$ $14.3 \mathrm{~Hz}, 1.8 \mathrm{~Hz}, 1 \mathrm{H}, \mathrm{H1}$ ), 4.56 (dd, $J=14.3 \mathrm{~Hz}, 7.4 \mathrm{~Hz}, 1 \mathrm{H}$, H1), 3.90-3.88 (m, 1H, H5), 3.78 (dd, $J=11.5 \mathrm{~Hz}, 7.3 \mathrm{~Hz}, 1 \mathrm{H}$, H7), 3.70 (dd, $J=11.3 \mathrm{~Hz}, 4.6 \mathrm{~Hz}, 1 \mathrm{H}, \mathrm{H} 7), 3.60-3.50$ (m, $4 \mathrm{H}), 2.41(\mathrm{~s}, 3 \mathrm{H}) ;{ }^{13} \mathrm{C} \mathrm{NMR}\left(100 \mathrm{MHz}, \mathrm{CD}_{3} \mathrm{OD}\right) \delta 147.4$, 138.4, 130.3, 128.6, 128.5, 125.9, 122.5, 122.2, 78.9, 78.8, 74.7, 69.4, 68.4, 61.5, 51.5, 20.1; HRMS $(\mathrm{m} / \mathrm{z}):[\mathrm{M}+\mathrm{H}]^{+}$calcd for
336.1553; found, 336.1559; purity by HPLC, UV-vis detection: $97.3 \%$.

1,2-Dideoxy-1-[4-(4-trifluoromethoxyphenyl)- $1 \mathrm{H}-1,2,3$ -

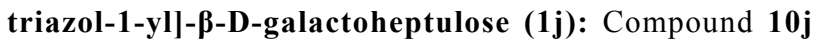
(77.3 mg, $0.101 \mathrm{mmol}$ ) was dissolved in cyclohexene/ethanol 2:1 (4.5 mL), palladium(II) hydroxide on charcoal (28 mg, $20 \mathrm{wt} \%$ ) was added, and the mixture was refluxed overnight at $80{ }^{\circ} \mathrm{C}$. The reaction mixture was diluted with methanol (15 mL), filtered through Celite, evaporated, purified by column chromatography (dichloromethane/methanol 5:1), and then preparative HPLC (gradient from 10\% acetonitrile/90\% water with $0.1 \%$ formic acid to $100 \%$ acetonitrile over $20 \mathrm{~min}$, followed by $3 \mathrm{~min}$ of $100 \%$ acetonitrile) to give $\mathbf{1 j}$ (40 $\mathrm{mg}, 89 \%$ ) as a white solid. $[\alpha]_{\mathrm{D}}{ }^{20} 7(c 0.9, \mathrm{MeOH}) ;{ }^{1} \mathrm{H}$ NMR $(400 \mathrm{MHz}$, $\left.\mathrm{CD}_{3} \mathrm{OD}\right) \delta 8.46(\mathrm{~s}, 1 \mathrm{H}), 7.96-7.91(\mathrm{~m}, 2 \mathrm{H}), 7.39-7.34(\mathrm{~m}, 2 \mathrm{H})$, $4.95(\mathrm{dd}, J=14.1 \mathrm{~Hz}, 2.0 \mathrm{~Hz}, 1 \mathrm{H}, \mathrm{H} 1), 4.57$ (dd, $J=14.0 \mathrm{~Hz}$, $7.5 \mathrm{~Hz}, 1 \mathrm{H}, \mathrm{H1}$ ), 3.90-3.88 (m, 1H, H5), 3.78 (dd, $J=11.4 \mathrm{~Hz}$, $7.3 \mathrm{~Hz}, 1 \mathrm{H}, \mathrm{H} 7), 3.70$ (dd, $J=11.5 \mathrm{~Hz}, 4.9 \mathrm{~Hz}, 1 \mathrm{H}, \mathrm{H} 7)$, 3.60-3.49 (m, 4H); ${ }^{13} \mathrm{C}$ NMR (100 MHz, $\left.\mathrm{CD}_{3} \mathrm{OD}\right) \delta 148.8$, $145.9,129.8,126.9,122.7,121.2,78.9,78.7,74.7,69.4,68.4$, $61.5,51.5 ;{ }^{19} \mathrm{~F}$ NMR (376 MHz, $\left.\mathrm{CD}_{3} \mathrm{OD}\right) \delta-59.49$; HRMS $(\mathrm{m} / \mathrm{z}):[\mathrm{M}+\mathrm{H}]^{+}$calcd for 406.1234 ; found, 406.1226 ; purity by HPLC, UV-vis detection: $99.8 \%$.

1,2-Dideoxy-1-[4-(4-trifluoromethylphenyl)-1 $H$-1,2,3-

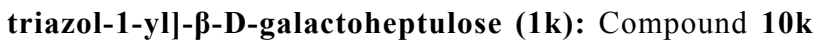
(51 mg, $0.067 \mathrm{mmol}$ ) was dissolved in cyclohexene/ethanol 2:1 (4.5 $\mathrm{mL})$, palladium(II) hydroxide on charcoal (38 $\mathrm{mg}$, $20 \mathrm{wt} \%$ ) was added, and the mixture refluxed overnight at $80{ }^{\circ} \mathrm{C}$. The reaction mixture was diluted with methanol $(15 \mathrm{~mL})$, filtered through Celite, evaporated, purified by column chromatography (dichloromethane/methanol 5:1), and then preparative HPLC (gradient from 10\% acetonitrile/90\% water with $0.1 \%$ formic acid to $100 \%$ acetonitrile over $20 \mathrm{~min}$, followed by $3 \mathrm{~min}$ of $100 \%$ acetonitrile) to give $1 \mathrm{k}(17 \mathrm{mg}, 63 \%)$ as a white solid. $[\alpha]_{\mathrm{D}}{ }^{20} 8(c 0.7, \mathrm{MeOH}) ;{ }^{1} \mathrm{H}$ NMR $(400 \mathrm{MHz}$, $\left.\mathrm{CD}_{3} \mathrm{OD}\right) \delta 8.55(\mathrm{~s}, 1 \mathrm{H}), 8.06-8.01(\mathrm{~m}, 2 \mathrm{H}), 7.78-7.73(\mathrm{~m}, 2 \mathrm{H})$, 4.97 (dd, $J=14.3 \mathrm{~Hz}, 2.0 \mathrm{~Hz}, 1 \mathrm{H}, \mathrm{H} 1), 4.59$ (dd, $J=14.3 \mathrm{~Hz}$, $7.6 \mathrm{~Hz}, 1 \mathrm{H}, \mathrm{H1}$ ), 3.91-3.88 (m, 1H, H5), 3.78 (dd, $J=11.8 \mathrm{~Hz}$, $7.2 \mathrm{~Hz}, 1 \mathrm{H}, \mathrm{H} 7), 3.70$ (dd, $J=11.8 \mathrm{~Hz}, 4.9 \mathrm{~Hz}, 1 \mathrm{H}, \mathrm{H} 7)$, 3.60-3.49 (m, 4H); ${ }^{13} \mathrm{C}$ NMR (100 MHz, $\left.\mathrm{CD}_{3} \mathrm{OD}\right) \delta 145.8$, 125.6, 125.50, 125.46, 123.3, 79.0, 78.7, 74.7, 69.4, 68.4, 61.5, $51.5 ;{ }^{19} \mathrm{~F}$ NMR (376 MHz, $\left.\mathrm{CD}_{3} \mathrm{OD}\right) \delta-64.13$; HRMS $(\mathrm{m} / \mathrm{z})$ : $[\mathrm{M}+\mathrm{H}]^{+}$calcd for 390.1279 ; found, 390.1277 ; purity by HPLC, UV-vis detection: $99.8 \%$.

1,2-Dideoxy-1-(4-naphth-1-yl-1H-1,2,3-triazol-1-yl)- $\beta$-Dgalactoheptulose (11): Compound 101 (12 mg, $0.016 \mathrm{mmol}$ ) was dissolved in cyclohexene/ethanol 2:1 (4.5 $\mathrm{mL})$, palladium(II) hydroxide on charcoal (10 mg, $20 \mathrm{wt} \%$ ) was 
added, and the mixture refluxed overnight at $80^{\circ} \mathrm{C}$. The reaction mixture was diluted with methanol $(15 \mathrm{~mL})$, filtered through Celite, evaporated, purified by column chromatography (dichloromethane/methanol 5:1), and then preparative HPLC (gradient from 10\% acetonitrile/90\% water with $0.1 \%$ formic acid to $100 \%$ acetonitrile over $20 \mathrm{~min}$, followed by $3 \mathrm{~min}$ of $100 \%$ acetonitrile) to give $\mathbf{1 l}(5 \mathrm{mg}, 79 \%)$ as a clear solid. $[\alpha]_{\mathrm{D}}{ }^{20} 22$ (c 0.5, MeOH); ${ }^{1} \mathrm{H}$ NMR (400 MHz, $\left.\mathrm{CD}_{3} \mathrm{OD}\right) \delta$ $8.43(\mathrm{~s}, 1 \mathrm{H}), 8.32-8.26(\mathrm{~m}, 1 \mathrm{H}), 7.98-7.93(\mathrm{~m}, 2 \mathrm{H}), 7.73(\mathrm{~d}$, $J=7.1 \mathrm{~Hz}, 1 \mathrm{H}), 7.60-7.53(\mathrm{~m}, 3 \mathrm{H}), 5.02(\mathrm{dd}, J=14.4 \mathrm{~Hz}$, $1.2 \mathrm{~Hz}, 1 \mathrm{H}, \mathrm{H} 1), 4.69$ (dd, $J=14.2 \mathrm{~Hz}, 7.6 \mathrm{~Hz}, 1 \mathrm{H}, \mathrm{H1}$ ), 3.91 (dd, $J=2.7 \mathrm{~Hz}, 1.0 \mathrm{~Hz}, 1 \mathrm{H}, \mathrm{H} 5), 3.81$ (dd, $J=11.8 \mathrm{~Hz}, 7.5 \mathrm{~Hz}$, 1H, H7), 3.71 (dd, $J=11.4 \mathrm{~Hz}, 4.8 \mathrm{~Hz}, 1 \mathrm{H}, \mathrm{H} 7), 3.67-3.61$ (m, $1 \mathrm{H}, \mathrm{HX}), 3.59-3.52(\mathrm{~m}, 3 \mathrm{H}) ;{ }^{13} \mathrm{C} \mathrm{NMR}\left(100 \mathrm{MHz}, \mathrm{CD}_{3} \mathrm{OD}\right) \delta$ 133.8, 131.2, 128.6, 128.1, 126.9, 126.3, 125.7, 125.3, 124.98, 124.95, 78.9, 78.6, 74.8, 69.5, 68.3, 61.6, 51.4; HRMS ( $\mathrm{m} / \mathrm{z})$ : $[\mathrm{M}+\mathrm{H}]^{+}$calcd for 372.1563 ; found, 372.1559 ; purity by HPLC, UV-vis detection: $96.3 \%$.

1,2-Dideoxy-1-[4-(4-biphenyl)-1H-1,2,3-triazol-1-yl]- $\beta$-Dgalactoheptulose (1m): Compound 10m (69 mg, $0.085 \mathrm{mmol})$ was dissolved in cyclohexene/ethanol 2:1 (4.5 mL), palladium(II) hydroxide on charcoal (9 $\mathrm{mg}, 20 \mathrm{wt} \%$ ) was added, and the mixture refluxed overnight at $80^{\circ} \mathrm{C}$. The reaction mixture was diluted with methanol $(15 \mathrm{~mL})$, filtered through Celite, evaporated, purified by column chromatography (dichloromethane/methanol 5:1), and then preparative HPLC (gradient from $10 \%$ acetonitrile/ $90 \%$ water with $0.1 \%$ formic acid to $100 \%$ acetonitrile over $20 \mathrm{~min}$, followed by $3 \mathrm{~min}$ of $100 \%$ acetonitrile) to give $\mathbf{1 m}(3 \mathrm{mg}, 10 \%)$ as a white powder. $[\alpha]_{\mathrm{D}}{ }^{20} 45$ (c $\left.0.7, \mathrm{MeOH}\right) ;{ }^{1} \mathrm{H}$ NMR $(400 \mathrm{MHz}$, $\left.\mathrm{CD}_{3} \mathrm{OD}\right) \delta 8.47(\mathrm{~s}, 1 \mathrm{H}), 7.95-7.90(\mathrm{~m}, 2 \mathrm{H}), 7.75-7.65(\mathrm{~m}, 4 \mathrm{H})$, 7.50-7.44 (m, 2H), 7.37 (tt, $J=7.4 \mathrm{~Hz}, 1.2 \mathrm{~Hz}, 1 \mathrm{H}), 4.97$ (dd, $J=14.2 \mathrm{~Hz}, 1.9 \mathrm{~Hz}, 1 \mathrm{H}, \mathrm{H1}), 4.58(\mathrm{dd}, J=14.0 \mathrm{~Hz}, 7.5 \mathrm{~Hz}$, 1H, H1), 3.92-3.89 (m, 1H, H5), 3.87-3.68 (m, 2H), 3.62-3.49 $(\mathrm{m}, 4 \mathrm{H}) ;{ }^{13} \mathrm{C}$ NMR $\left(100 \mathrm{MHz}, \mathrm{CD}_{3} \mathrm{OD}\right) \delta 147.0,140.9,140.4$, $128.5,127.2,127.1,126.5,125.7,122.3,78.9,78.8,74.7$, 69.4, 68.4, 61.5, 51.5; HRMS $(\mathrm{m} / \mathrm{z}):[\mathrm{M}+\mathrm{H}]^{+}$calcd for 398.1717; found, 398.1716; purity by HPLC, UV-vis detection: $99.7 \%$.

1,2-Dideoxy-1-(4-naphth-2-yl-1H-1,2,3-triazol-1-yl)- $\beta$-Dgalactoheptulose (1n): Compound 10n (96 mg, $0.131 \mathrm{mmol})$ was dissolved in cyclohexene/ethanol 2:1 (6 mL), palladium(II) hydroxide on charcoal (73 $\mathrm{mg}, 20 \mathrm{wt} \%$ ) was added, and the mixture refluxed overnight at $80{ }^{\circ} \mathrm{C}$. The reaction mixture was diluted with methanol $(15 \mathrm{~mL})$, filtered through Celite, evaporated, purified by column chromatography (dichloromethane/ methanol 5:1), and then preparative HPLC (gradient from 10\% acetonitrile $/ 90 \%$ water with $0.1 \%$ formic acid to $100 \%$ acetonitrile over $20 \mathrm{~min}$, followed by $3 \mathrm{~min}$ of $100 \%$ acetonitrile) to give $1 \mathrm{n}(26 \mathrm{mg}, 54 \%)$ as a clear solid. $[\alpha]_{\mathrm{D}}{ }^{20} 12(c 0.7, \mathrm{MeOH})$; ${ }^{1} \mathrm{H}$ NMR (400 MHz, CD $\mathrm{CD}_{3} \delta 8.54(\mathrm{~s}, 1 \mathrm{H}), 8.32(\mathrm{~s}, 1 \mathrm{H})$, 7.97-7.85 (m, 4H), 7.54-7.47 (m, 2H), $4.98(\mathrm{dd}, J=14.2 \mathrm{~Hz}$, $2.0 \mathrm{~Hz}, 1 \mathrm{H}, \mathrm{H1}), 4.60$ (dd, $J=14.2 \mathrm{~Hz}, 7.5 \mathrm{~Hz}, 1 \mathrm{H}, \mathrm{H} 1), 3.91$ (dd, $J=2.8 \mathrm{~Hz}, 1.0 \mathrm{~Hz}, 1 \mathrm{H}, \mathrm{H} 5), 3.81$ (dd, $J=12.0 \mathrm{~Hz}, 7.3 \mathrm{~Hz}$, 1H, H7), 3.72 (dd, $J=12.0 \mathrm{~Hz}, 4.9 \mathrm{~Hz}, \mathrm{H} 7), 3.63-3.51$ (m, $4 \mathrm{H}) ;{ }^{13} \mathrm{C} \mathrm{NMR}\left(100 \mathrm{MHz}, \mathrm{CD}_{3} \mathrm{OD}\right) \delta 147.3,133.6,133.2$, $128.3,127.80,127.75,127.4,126.2,125.9,123.9,123.4,122.6$, 79.0, 78.8, 74.8, 69.5, 68.4, 61.5, 51.5; $\operatorname{HRMS}(m / z):[\mathrm{M}+\mathrm{H}]^{+}$ calcd for 372.1557 ; found, 372.1559 ; purity by HPLC, UV-vis detection: $99.5 \%$.

3,4,5,7-Tetra-O-benzyl-2-deoxy- $\boldsymbol{\beta}$-D-galactoheptulose (3): Compound 2 ( $3.66 \mathrm{~g}, 6.82 \mathrm{mmol}$ ) was dissolved in dry tetrahydrofuran $(130 \mathrm{~mL})$ under nitrogen and cooled to $0{ }^{\circ} \mathrm{C}$. Borane dimethyl sulfide complex in dry tetrahydrofuran $(4.78 \mathrm{~mL}$, $9.55 \mathrm{mmol}, 2 \mathrm{M}$ ) was added slowly, and the reaction was kept at $0{ }^{\circ} \mathrm{C}$ for $2 \mathrm{~h}$. The reaction mixture went from light yellow to colorless during the addition of the borane dimethyl sulfide complex. Upon complete consumption of $\mathbf{2}$, distilled water $(15 \mathrm{~mL})$ was added to the reaction mixture slowly (dropwise at first) while vigorous gas evolution was observed. After completion of the gas evolution, sodium hydroxide $(14 \mathrm{~mL}$, $14.00 \mathrm{mmol}, 1 \mathrm{M})$ and hydrogen peroxide $(33 \%, 2 \mathrm{~mL}$, $20.5 \mathrm{mmol}$ ) were added, and the reaction mixture left for $2 \mathrm{~h}$. Upon completion of the reaction, $1 \mathrm{M}$ hydrochloric acid was added to the reaction mixture until the $\mathrm{pH}$ was approximately 7 . The reaction mixture was poured into brine $(150 \mathrm{~mL})$, extracted with dichloromethane $(3 \times 150 \mathrm{~mL})$ after which the organic phases were pooled, dried with anhydrous sodium sulfate, filtered, and evaporated. The crude was purified with column chromatography (heptane/ethyl acetate 1:1) to give 3 (3.38 g, $89 \%$ ) as a clear, viscous oil. The diastereoselectivity was determined to be $\alpha: \beta 1: 19$ by HPLC, using the same protocol as is used for purity determinations. The stereochemistry of the $\beta$ diastereomer, the only one isolated, was assigned using NOESY. $[\alpha]_{\mathrm{D}}{ }^{20} 31\left(c 1, \mathrm{CH}_{2} \mathrm{Cl}_{2}\right) ;{ }^{1} \mathrm{H} \mathrm{NMR}\left(400 \mathrm{MHz}, \mathrm{CDCl}_{3}\right)$

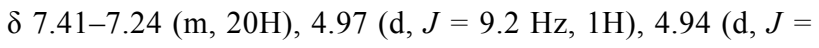
$8.4 \mathrm{~Hz}, 1 \mathrm{H}), 4.78(\mathrm{~d}, J=11.9 \mathrm{~Hz}, 1 \mathrm{H}), 4.71(\mathrm{~d}, J=11.9 \mathrm{~Hz}$, 1H), 4.67 (d, $J=10.9 \mathrm{~Hz}, 1 \mathrm{H}), 4.62(\mathrm{~d}, J=11.6 \mathrm{~Hz}, 1 \mathrm{H}), 4.49$ $(\mathrm{d}, J=11.6 \mathrm{~Hz}, 1 \mathrm{H}), 4.43$ (d, $J=11.9 \mathrm{~Hz}, 1 \mathrm{H}), 3.99$ (d, $J=$ $2.7 \mathrm{~Hz}, 1 \mathrm{H}, \mathrm{H} 5), 3.95$ (d, $J=9.4 \mathrm{~Hz}, 1 \mathrm{H}, \mathrm{H} 3), 3.87$ (dd, $J=$ $11.9 \mathrm{~Hz}, 2.7 \mathrm{~Hz}, 1 \mathrm{H}, \mathrm{H1}), 3.71$ (dd, $J=11.7 \mathrm{~Hz}, 5.2 \mathrm{~Hz}, 1 \mathrm{H}$, H1), 3.65 (dd, $J=9.4 \mathrm{~Hz}, 2.7 \mathrm{~Hz}, 1 \mathrm{H}, \mathrm{H} 4), 3.62-3.50$ (m, 3H), 3.40-3.33 (m, 1H, H2); ${ }^{13} \mathrm{C} \mathrm{NMR}\left(100 \mathrm{MHz}, \mathrm{CDCl}_{3}\right) \delta 138.7$, 138.32, 138.26, 137.8, 128.5, 128.5, 128.3, 128.2, 128.1, 128.0, $127.89,127.85,127.72,127.65,127.6,84.7,79.6,77.0,75.4$, 75.3, 74.6, 73.8, 73.6, 72.4, 69.0, 62.6; ${ }^{1} \mathrm{H}$ NMR (400 MHz, pyridine- $\left.d_{5}\right) \delta 7.60-7.20(\mathrm{~m}, 20 \mathrm{H}), 5.19(\mathrm{~d}, J=11.1 \mathrm{~Hz}, 1 \mathrm{H})$, $5.13(\mathrm{~d}, J=11.1 \mathrm{~Hz}, 1 \mathrm{H}), 4.94-4.86(\mathrm{~m}, 2 \mathrm{H}), 4.79(\mathrm{~d}, J=$ $11.1 \mathrm{~Hz}, 2 \mathrm{H}), 4.60-4.48$ (m, 3H), 4.43 (t, $J=9.1 \mathrm{~Hz}, 1 \mathrm{H}, \mathrm{H} 2)$, 
$4.32-4.25(\mathrm{~m}, 2 \mathrm{H}), 4.14(\mathrm{dd}, J=11.7 \mathrm{~Hz}, 4.6 \mathrm{~Hz}, 1 \mathrm{H}, \mathrm{H} 3)$, $3.95-3.85(\mathrm{~m}, 3 \mathrm{H}), 3.77(\mathrm{dd}, J=7.6 \mathrm{~Hz}, 4.3 \mathrm{~Hz}, 1 \mathrm{H}, \mathrm{H} 1)$, $3.70-3.64(\mathrm{~m}, 1 \mathrm{H}) ;{ }^{13} \mathrm{C}$ NMR $\left(100 \mathrm{MHz}\right.$, pyridine- $\left.d_{5}\right) \delta 139.6$, $139.5,139.2,138.8,132.53,132.46,130.0,128.57,128.55$, $128.5,128.4,128.3,128.2,128.11,128.06,128.04,127.99$, $127.8,127.7,127.6,127.5,85.0,81.7,77.1,75.8,75.1,75.0$, $75.1,73.3,72.0,69.5,62.1$; HRMS $(m / z):[\mathrm{M}+\mathrm{Na}]^{+}$calcd for 577.2526; found, 577.2566.

3,4,5,7-Tetra-O-benzyl-2-deoxy- $\beta$-D-mannoheptulose (5): Compound 4 ( $35 \mathrm{mg}, 0.065 \mathrm{mmol}$ ) was dissolved in dry tetrahydrofuran $(3 \mathrm{~mL})$ under nitrogen and cooled to $0{ }^{\circ} \mathrm{C}$. Borane dimethyl sulfide complex in dry tetrahydrofuran $(40 \mu \mathrm{L}$, $0.078 \mathrm{mmol}, 2 \mathrm{M}$ ) was added slowly and the reaction was kept at $0{ }^{\circ} \mathrm{C}$ for $2 \mathrm{~h}$. The reaction mixture went from light yellow to colorless during the addition of the borane dimethyl sulfide complex. Upon complete consumption of the starting material, distilled water $(0.66 \mathrm{~mL})$ was added to the reaction mixture slowly (dropwise at first) while vigorous gas evolution was observed. After completion of the gas evolution, sodium hydroxide $(131 \mu \mathrm{L}, 0.131 \mathrm{mmol}, 1 \mathrm{M})$ and hydrogen peroxide $(33 \%$, $13 \mu \mathrm{L}, 0.131 \mathrm{mmol}$ ) were added, and the reaction mixture left for $2 \mathrm{~h}$. Upon completion of the reaction, $1 \mathrm{M}$ hydrochloric acid was added to the reaction mixture until the $\mathrm{pH}$ was approximately 7 . The reaction mixture was poured into brine $(30 \mathrm{~mL})$, extracted with dichloromethane $(3 \times 30 \mathrm{~mL})$ after which the organic phases were pooled, dried with anhydrous sodium sulfate, filtered and evaporated. The crude was purified with column chromatography (heptane/ethyl acetate 1:1) to give 5 (28 mg, 78\%) as a clear, viscous oil. The diastereoselectivity was determined to be $\alpha: \beta 1: 99$ by HPLC, using the same protocol as is used for purity determinations. The stereochemistry of the $\beta$ diastereomer, the only one isolated, was assigned using NOESY. $[\alpha]_{\mathrm{D}}{ }^{20}-37\left(c 0.1, \mathrm{CH}_{3} \mathrm{CN}\right) ;{ }^{1} \mathrm{H}$ NMR $\left(400 \mathrm{MHz}, \mathrm{CDCl}_{3}\right) \delta 7.43-7.26(\mathrm{~m}, 18 \mathrm{H}), 7.22-7.18(\mathrm{~m}, 2 \mathrm{H})$, $5.00(\mathrm{~d}, J=12.0 \mathrm{~Hz}, 1 \mathrm{H}), 4.91(\mathrm{~d}, 10.7 \mathrm{~Hz}, 1 \mathrm{H}), 4.83-4.74(\mathrm{~m}$, 2H), 4.72-4.54 (m, 4H), 3.95 (t, J = 9.8 Hz, 1H, H5), 3.90 (d, $2.6 \mathrm{~Hz}, 1 \mathrm{H}, \mathrm{H} 3), 3.87-3.70(\mathrm{~m}, 3 \mathrm{H}), 3.65(\mathrm{dd}, J=9.4 \mathrm{~Hz}$, $2.7 \mathrm{~Hz}, 1 \mathrm{H}, \mathrm{H} 6), 3.54-3.47$ (m, 2H), 3.44 (t, $J=5.7 \mathrm{~Hz}, 1 \mathrm{H}$, $\mathrm{H} 2) ;{ }^{13} \mathrm{C} \mathrm{NMR}\left(100 \mathrm{MHz}, \mathrm{CDCl}_{3}\right) \delta 138.4,138.2,128.53$, $128.45,128.37,128.35,128.1,127.94,127.89,127.8,127.7$, $127.62,127.59,85.0,79.6,78.6,75.4,75.3,74.1,73.5,73.3$, $72.7,69.6,62.5 ;{ }^{1} \mathrm{H}$ NMR (400 MHz, pyridine- $\left.d_{5}\right) \delta 7.43-7.22$ $(\mathrm{m}, 20 \mathrm{H}), 5.23(\mathrm{~d}, J=11.2 \mathrm{~Hz}, 1 \mathrm{H}), 5.10(\mathrm{~d}, J=11.2 \mathrm{~Hz}, 1 \mathrm{H})$, 4.93-4.87 (partially obscured by solvent), 4.80-4.64 (m, 3H), 4.56 (d, $J=4.56 \mathrm{~Hz}, 1 \mathrm{H}), 4.48$ (d, $J=2.9 \mathrm{~Hz}, 1 \mathrm{H}, \mathrm{H} 3), 4.32$ (t, $J=9,5 \mathrm{~Hz}, 1 \mathrm{H}, \mathrm{H} 4), 4.27(\mathrm{~m}, 1 \mathrm{H}, \mathrm{H} 1), 4.18(\mathrm{~m}, 1 \mathrm{H}, \mathrm{H} 1)$, 3.95-3.88 (m, 4H), $3.76(\mathrm{dt}, J=9.5 \mathrm{~Hz}, 3.4 \mathrm{~Hz}, 1 \mathrm{H}, \mathrm{H} 5)$; ${ }^{13} \mathrm{C}$ NMR $\left(100 \mathrm{MHz}\right.$, pyridine- $\left.d_{5}\right) \delta 141.3,140.9,140.7$, $140.6,130.1,129.90,129.86,129.49,129.45,129.2,129.1$, $128.99,128.95,86.7,81.4,81.3,77.4,76.5,76.4,74.8,73.3$,
71.8, 62.9; HRMS $(m / z):[\mathrm{M}+\mathrm{H}]^{+}$calcd for 555.2743; found, 555.2747 .

\section{3,4,5,7-Tetra- $O$-benzyl-2-deoxy- $\beta$-D-glucoheptulose (7):}

Compound 6 ( $67 \mathrm{mg}, 0.125 \mathrm{mmol}$ ) was dissolved in dry tetrahydrofuran $(3 \mathrm{~mL})$ under nitrogen and cooled to $0{ }^{\circ} \mathrm{C}$. Borane dimethyl sulfide complex in dry tetrahydrofuran $(75 \mu \mathrm{L}$, $0.150 \mathrm{mmol}, 2 \mathrm{M}$ ) was added slowly and the reaction was kept at $0{ }^{\circ} \mathrm{C}$ for $2 \mathrm{~h}$. The reaction mixture went from light yellow to colorless during the addition of the borane dimethyl sulfide complex. Upon complete consumption of the starting material, distilled water $(0.66 \mathrm{~mL})$ was added to the reaction mixture slowly (dropwise at first) while vigorous gas evolution was observed. After completion of the gas evolution, sodium hydroxide $(250 \mu \mathrm{L}, 0.251 \mathrm{mmol}, 1 \mathrm{M})$ and hydrogen peroxide $(33 \%$, $25 \mu \mathrm{L}, 0.251 \mathrm{mmol})$ were added, and the reaction mixture left for $2 \mathrm{~h}$. Upon completion of the reaction, $1 \mathrm{M}$ hydrochloric acid was added to the reaction mixture until the $\mathrm{pH}$ was approximately 7 . The reaction mixture was poured into brine $(30 \mathrm{~mL})$, extracted with dichloromethane $(3 \times 30 \mathrm{~mL})$ after which the organic phases were pooled, dried with anhydrous sodium sulfate, filtered and evaporated. The crude was purified with column chromatography (heptane/ethyl acetate 1:1) to give 7 (31 mg, 45\%) as a diastereomeric mixture. Three consecutive preparative HPLC purifications gave $3 \mathrm{mg}$ of pure $\alpha-7,17 \mathrm{mg}$ of pure $\beta$-7, and $11 \mathrm{mg}$ of $7 \alpha / \beta$-mixture as clear and viscous oils. The diastereoselectivity was determined to be $\alpha: \beta 1: 2.3$ by HPLC using the same protocol as is used for purity determinations. The stereochemistry was assigned using NOESY. Data for $\alpha-7:[\alpha]_{\mathrm{D}}{ }^{20} 52\left(c 0.2, \mathrm{CH}_{3} \mathrm{CN}\right)$; ${ }^{1} \mathrm{H}$ NMR (400 MHz, acetone- $\left.d_{6}\right) \delta 7.44-7.24(\mathrm{~m}, 20 \mathrm{H}), 4.93(\mathrm{~d}, J=11.5 \mathrm{~Hz}, 1 \mathrm{H}), 4.84$ $(\mathrm{d}, J=11.0 \mathrm{~Hz}, 1 \mathrm{H}), 4.81(\mathrm{~d}, J=11.3 \mathrm{~Hz}, 1 \mathrm{H}), 4.76(\mathrm{~m}, 2 \mathrm{H})$, 4.66-4.53 (m, 3H), 4.18-4.12 (m, 1H), 4.08-4.00 (m, 1H), 3.93-3.69 (m, 5H), 3.64-3.56 (m, 2H); ${ }^{13} \mathrm{C}$ NMR (100 MHz, acetone- $\left.d_{6}\right) \delta 139.3,139.0,138.9,138.8,128.3,128.2,128.13$, $128.11,127.8,127.7,127.6,127.5,127.32,127.29,127.2,82.4$, 79.5, 78.3, 74.6, 74.6, 74.3, 72.9, 72.6, 72.4, 69.6, 57.9, 57.8; ${ }^{1} \mathrm{H}$ NMR (400 MHz, pyridine- $\left.d_{5}\right) \delta 7.51-7.23(\mathrm{~m}, 20 \mathrm{H})$, 5.09-5.01 (m, 2H), 5.00-4.91 (m, 2H, obstructed by solvent), $4.81-4.75(\mathrm{~m}, 3 \mathrm{H}), 4.69-4.53(\mathrm{~m}, 3 \mathrm{H}), 4.48(\mathrm{t}, J=8.1 \mathrm{~Hz}, 1 \mathrm{H}$, H3), 4.37 (ddd, $J=9.9 \mathrm{~Hz}, 4.0 \mathrm{~Hz}, 1.9 \mathrm{~Hz}, 1 \mathrm{H}, \mathrm{H} 6), 4.34-4.27$ $(\mathrm{m}, 2 \mathrm{H}), 4.04(\mathrm{dd}, J=8.9 \mathrm{~Hz}, 5.9 \mathrm{~Hz}, 1 \mathrm{H}, \mathrm{H} 2), 3.98-3.88(\mathrm{~m}$, $2 \mathrm{H}), 3.85(\mathrm{dd}, J=10.8 \mathrm{~Hz}, 2.2 \mathrm{~Hz}, 1 \mathrm{H}, \mathrm{H} 7) ;{ }^{13} \mathrm{C} \mathrm{NMR}$ $\left(100 \mathrm{MHz}\right.$, pyridine- $\left.d_{5}\right) \delta 141.1,140.8,140.6,140.4,130.01$, $129.99,129.97,129.95,129.52,129.49,129.45,129.40,129.3$, 129.12, 129.10, 84.4, 81.6, 80.3, 77.1, 76.3, 76.1, 74.8, 74.7, 74.5, 71.5, 60.2; HRMS $(\mathrm{m} / \mathrm{z}):[\mathrm{M}+\mathrm{H}]^{+}$calcd for 555.2755; found, 555.2747. Data for $\beta-7:[\alpha]_{\mathrm{D}}{ }^{20} 20\left(c 1.1, \mathrm{CH}_{3} \mathrm{CN}\right)$; ${ }^{1} \mathrm{H}$ NMR (400 MHz, acetone- $d_{6}$ ) $\delta 7.43-7.24(\mathrm{~m}, 20 \mathrm{H}), 4.93$ (s, $2 \mathrm{H}), 4.89(\mathrm{~d}, J=7.8 \mathrm{~Hz}, 1 \mathrm{H}), 4.86(\mathrm{~d}, J=7.6 \mathrm{~Hz}, 1 \mathrm{H}), 4.75$ (d, $J=11.1 \mathrm{~Hz}, 1 \mathrm{H}), 4.67(\mathrm{~d}, J=10.9 \mathrm{~Hz}, 1 \mathrm{H}), 3.87(\mathrm{~m}, 1 \mathrm{H})$, 
3.80-3.68 (m, 4H), $3.60(\mathrm{td}, J=9.3 \mathrm{~Hz}, 2.2 \mathrm{~Hz}, 2 \mathrm{H}), 3.51$ (ddd, $J=9.7 \mathrm{~Hz}, 3.8 \mathrm{~Hz}, 2.3 \mathrm{~Hz}, 1 \mathrm{H}), 3.36(\mathrm{ddd}, J=9.7 \mathrm{~Hz}, 4.2 \mathrm{~Hz}$, $2.2 \mathrm{~Hz}, 1 \mathrm{H}) ;{ }^{13} \mathrm{C}$ NMR $\left(100 \mathrm{MHz}\right.$, acetone- $\left.d_{6}\right) \delta 139.2,139.0$, $138.9,138.8,128.20,128.17,128.15,127.73,127.71,127.69$, $127.5,127.4,127.34,127.26,87.1,80.1,78.9,78.6,78.4,74.9$, $74.43,74.36,73.0,69.4,61.4,61.3 ;{ }^{1} \mathrm{H}$ NMR (400 MHz, pyridine- $\left.d_{5}\right) \delta 7.52-7.41(\mathrm{~m}, 6 \mathrm{H}), 7.40-7.23(\mathrm{~m}, 14 \mathrm{H}), 5.10-4.94$ (m, partially solvent obstructed), $4.77(\mathrm{~d}, J=11.2 \mathrm{~Hz}, 1 \mathrm{H}), 4.63$ $(\mathrm{d}, J=11.9 \mathrm{~Hz}, 1 \mathrm{H}), 4.55(\mathrm{~d}, J=12.0 \mathrm{~Hz}, 1 \mathrm{H}), 4.27(\mathrm{~d}, J=$ $12.1 \mathrm{~Hz}, 1 \mathrm{H}, \mathrm{H1}), 4.11(\mathrm{dd}, J=11.6 \mathrm{~Hz}, 4.1 \mathrm{~Hz}, 1 \mathrm{H}, \mathrm{H} 1)$, 4.04-3.85 (m, 5H), 3.73 (dt, $J=9.4 \mathrm{~Hz}, 2.9 \mathrm{~Hz}, 1 \mathrm{H}, \mathrm{H} 6), 3.65$ $(\mathrm{m}, 1 \mathrm{H}, \mathrm{H} 2) ;{ }^{13} \mathrm{C}$ NMR (100 MHz, pyridine- $\left.d_{5}\right) \delta 139.5,139.3$, $139.1,138.8,128.51,128.48,128.47,127.97,127.95,127.8$, 127.7, 127.62, 127.55, 87.4, 81.2, 79.1, 78.81, 78.75, 75.2, 74.7, $73.3,69.9,61.5$; HRMS $(\mathrm{m} / \mathrm{z}):[\mathrm{M}+\mathrm{H}]^{+}$calcd for 555.2745 ; found, 555.2747 .

3,4,5,7-Tetra-O-benzyl-2-deoxy-1-methanesulfonyl- $\beta$-Dgalactoheptulose (8): Compound 3 (3.38 g, $6.08 \mathrm{mmol})$ was dissolved in dry pyridine $(16.5 \mathrm{~mL})$ under nitrogen and cooled to $0{ }^{\circ} \mathrm{C}$. Methanesulfonyl chloride $(1.55 \mathrm{~mL}, 20.10 \mathrm{mmol})$ was added slowly. The reaction mixture turns yellow/orange upon addition. The reaction was left for $2 \mathrm{~h}$, after which the reaction mixture was poured into brine $(200 \mathrm{~mL}$ with $20 \mathrm{~mL} \mathrm{5 \%}$ hydrochloric acid), extracted with dichloromethane $(3 \times 200 \mathrm{~mL})$ after which the organic phases were pooled. The organic phases were washed once with brine, dried with anhydrous sodium sulfate, filtered and evaporated. The crude was purified with column chromatography (heptane/ethyl acetate $1: 1)$ to give $\mathbf{8}$ $(3.51 \mathrm{~g}, 91 \%)$ as a cream white solid. $[\alpha]_{\mathrm{D}}{ }^{20} 7\left(c 1.1, \mathrm{CH}_{2} \mathrm{Cl}_{2}\right)$; ${ }^{1} \mathrm{H}$ NMR (400 MHz, $\left.\mathrm{CDCl}_{3}\right) \delta 7.52-7.25(\mathrm{~m}, 20 \mathrm{H}), 5.06(\mathrm{~d}, J=$ $4.0 \mathrm{~Hz}, 1 \mathrm{H}), 5.04(\mathrm{~d}, J=4.6 \mathrm{~Hz}, 1 \mathrm{H}), 4.88(\mathrm{~d}, J=11.6 \mathrm{~Hz}$, $1 \mathrm{H}), 4.80(\mathrm{~d}, J=12.2 \mathrm{~Hz}, 1 \mathrm{H}), 4.75(\mathrm{~d}, J=10.7 \mathrm{~Hz}, 1 \mathrm{H})$, $4.67-4.61(\mathrm{~m}, 2 \mathrm{H}), 4.58-4.52(\mathrm{~m}, 2 \mathrm{H}), 4.47\left(\mathrm{dd}, J^{1}=12.2 \mathrm{~Hz}\right.$, $4.9 \mathrm{~Hz}, \mathrm{H1}), 4.09$ (d, $J=2.7 \mathrm{~Hz}, 1 \mathrm{H}, \mathrm{H} 5), 4.03$ (t, $J=9.7 \mathrm{~Hz}$, $1 \mathrm{H}, \mathrm{H} 3), 3.73\left(\mathrm{dd}, J^{1}=9.1,2.7 \mathrm{~Hz}, 1 \mathrm{H}, \mathrm{H} 4\right), 3.71-3.54(\mathrm{~m}$, $4 \mathrm{H}), 2.99(\mathrm{~s}, 3 \mathrm{H}) ;{ }^{13} \mathrm{C} \mathrm{NMR}\left(100 \mathrm{MHz}, \mathrm{CDCl}_{3}\right) \delta 138.5,138.1$, $138.0,137.8,128.63,128.60,128.4,128.3,128.16,128.04$, $128.02,127.92,127.86,127.7,84.5,77.7,77.2,75.5,74.8,74.2$, $73.7,73.6,72.3,69.9,68.8,38.0$; HRMS $(m / z):[\mathrm{M}+\mathrm{Na}]^{+}$ calcd for 655.2343 ; found, 655.2342 .

1-Azido-3,4,5,7-tetra- $O$-benzyl-1,2-dideoxy- $\beta$-D-galactoheptulose (9): Compound 8 (3.51 g, $5.55 \mathrm{mmol})$ was dissolved in dry DMF (40 mL) and sodium azide (791 mg, $12.17 \mathrm{mmol})$ was added. The reaction mixture was heated to $95{ }^{\circ} \mathrm{C}$ and left overnight. Upon completion, the reaction mixture was poured into distilled water $(500 \mathrm{~mL})$ and washed with dichloromethane $(3 \times 150 \mathrm{~mL})$. The organic phases were pooled and washed with brine $(450 \mathrm{~mL})$, dried with anhydrous sodium sulfate, and evaporated. The crude was purified with column chromatography (heptane/ethyl acetate 1:1) to give $9(2.90 \mathrm{~g}, 90 \%)$ as a clear, viscous oil that after about two weeks crystallized into a greywhite sticky solid. $[\alpha]_{\mathrm{D}}{ }^{20}-5\left(c 1.1, \mathrm{CH}_{2} \mathrm{Cl}_{2}\right)$; IR v: $2101 \mathrm{~cm}^{-1}$, azide; ${ }^{1} \mathrm{H}$ NMR (400 MHz, $\left.\mathrm{CDCl}_{3}\right) \delta 7.45-7.25(\mathrm{~m}, 20 \mathrm{H}), 5.00$ $(\mathrm{d}, J=3.3 \mathrm{~Hz}, 1 \mathrm{H}), 4.97(\mathrm{~d}, J=2.5 \mathrm{~Hz}, 1 \mathrm{H}), 4.80(\mathrm{~d}, J=11.7$ $\mathrm{Hz}, 1 \mathrm{H}), 4.71(\mathrm{~d}, J=12.0 \mathrm{~Hz}, 1 \mathrm{H}), 4.68-4.61(\mathrm{~m}, 2 \mathrm{H}), 4.52(\mathrm{~d}$, $J=11.7 \mathrm{~Hz}, 1 \mathrm{H}), 4.56(\mathrm{~d}, J=11.7 \mathrm{~Hz}, 1 \mathrm{H}), 4.04(\mathrm{~d}, J=$ $2.6 \mathrm{~Hz}, 1 \mathrm{H}, \mathrm{H} 5), 3.90$ (t, $J=9.4 \mathrm{~Hz}, 1 \mathrm{H}, \mathrm{H} 3), 3.67-3.58$ (m, $4 \mathrm{H}), 3.53-3.46(\mathrm{~m}, 2 \mathrm{H}), 3.39(\mathrm{dd}, J=12.4 \mathrm{~Hz}, 7.2 \mathrm{~Hz}, 1 \mathrm{H}$, $\mathrm{H} 1) ;{ }^{13} \mathrm{C} \mathrm{NMR}\left(100 \mathrm{MHz}, \mathrm{CDCl}_{3}\right) \delta 138.7,138.2,138.1,137.9$, $128.50,128.46,128.3,128.2,127.97,127.96,127.9,127.8$, $127.8,127.6,84.6,79.1,77.2,75.7,75.4,74.5,73.62,73.55$, 72.2, 69.0, 51.5; HRMS $(m / z):[\mathrm{M}+\mathrm{Na}]^{+}$calcd for 602.2634 found, 602.2631 .

3,4,5,7-Tetra-O-benzyl-1,2-dideoxy-1-[4-phenyl-1 $\mathrm{H}$-1,2,3-

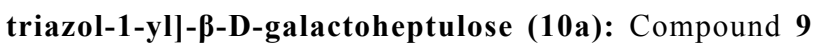
(100 mg, $0.184 \mathrm{mmol}$ ) and copper(I) iodide (4 mg, $0.035 \mathrm{mmol}$ ) were dissolved in dry acetonitrile $(3 \mathrm{~mL})$ under nitrogen, triethylamine $(52 \mu \mathrm{L}, 0.368 \mathrm{mmol})$ and ethynylbenzene $(22 \mu \mathrm{L}$, $0.194 \mathrm{mmol}$ ) were added, and the reaction was left at $55^{\circ} \mathrm{C}$ overnight. Upon completion, the reaction mixture was poured into ethyl acetate $(20 \mathrm{~mL})$ and washed with brine $(20 \mathrm{~mL})$. The brine was extracted with ethyl acetate $(2 \times 20 \mathrm{~mL})$, the organic phases pooled, dried with anhydrous sodium sulfate, and evaporated. The crude product was purified with column chromatography (heptane/ethyl acetate $2: 1$ ) to give $\mathbf{1 0 a}(96.8 \mathrm{mg}, 77 \%$ ) as a viscous clear oil. $[\alpha]_{\mathrm{D}}{ }^{20}-10\left(c 1.9, \mathrm{CH}_{2} \mathrm{Cl}_{2}\right) ;{ }^{1} \mathrm{H} \mathrm{NMR}$ $\left(400 \mathrm{MHz}, \mathrm{CDCl}_{3}\right) \delta 8.01(\mathrm{~s}, 1 \mathrm{H}), 7.81-7.75(\mathrm{~m}, 2 \mathrm{H})$, $7.45-7.14(\mathrm{~m}, 23 \mathrm{H}), 4.97(\mathrm{~d}, J=7.4 \mathrm{~Hz}, 1 \mathrm{H}), 4.94(\mathrm{~d}, J=$ $6.2 \mathrm{~Hz}, 1 \mathrm{H}), 4.81(\mathrm{~d}, J=11.7 \mathrm{~Hz}, 1 \mathrm{H}), 4.76-4.68(\mathrm{~m}, 4 \mathrm{H}), 4.57$ $(\mathrm{d}, J=11.7 \mathrm{~Hz}, 1 \mathrm{H}), 4.51-4.48(\mathrm{~m}, 2 \mathrm{H}), 4.00(\mathrm{~s}, 1 \mathrm{H}, \mathrm{H} 5)$, $3.75-3.55(\mathrm{~m}, 6 \mathrm{H}) ;{ }^{13} \mathrm{C} \mathrm{NMR}\left(100 \mathrm{MHz}, \mathrm{CDCl}_{3}\right) \delta 138.5$, $138.01,137.95,137.8,132.80,132.2,131.0,129.2,128.8$, $128.7,128.6,128.54,128.50,128.4,128.3,128.0,127.91$, $127.87,127.85,127.7,127.6,127.54,127.52,125.8,121.4$, 84.5, 77.7, 77.2, 75.4, 74.8, 74.6, 73.8, 73.6, 72.2, 69.1, 51.1; HRMS $(\mathrm{m} / \mathrm{z}):[\mathrm{M}+\mathrm{H}]^{+}$calcd for 682.3288 ; found, 682.3281 .

3,4,5,7-Tetra- $O$-benzyl-1,2-dideoxy-1-[4-(4-fluorophenyl)$1 \mathrm{H}-1,2,3$-triazol-1-yl]- $\beta$-D-galactoheptulose (10b): Compound 9 (113 mg, $0.198 \mathrm{mmol})$, 1-ethynyl-4-fluorobenzene (29 mg, $0.238 \mathrm{mmol}$ ), and copper(I) iodide (4 mg, $0.035 \mathrm{mmol}$ ) were dissolved in dry acetonitrile $(3 \mathrm{~mL})$ under nitrogen, triethylamine ( $55 \mu \mathrm{L}, 0.397 \mathrm{mmol})$ was added, and the reaction left at room temperature overnight. Upon completion, the reaction mixture was poured into ethyl acetate $(20 \mathrm{~mL})$ and washed with brine $(20 \mathrm{~mL})$. The brine was extracted with ethyl acetate $(2 \times 20 \mathrm{~mL})$, the organic phases pooled, dried with anhydrous sodium sulfate, and evaporated. The crude product was purified with column chromatography (heptane/ethyl acetate $3: 1$ ) to give 
10b (97 mg, 70\%) as a viscous lightly yellow oil. $[\alpha]_{\mathrm{D}}{ }^{20}-13(\mathrm{c}$ $\left.0.7, \mathrm{CH}_{2} \mathrm{Cl}_{2}\right) ;{ }^{1} \mathrm{H}$ NMR $\left(400 \mathrm{MHz}, \mathrm{CDCl}_{3}\right) \delta 7.95(\mathrm{~s}, 1 \mathrm{H}), 7.73$ (m, 2H), 7.44-7.15 (m, 20H), 7.10-7.03 (m, 2H), 4.96 (d, $J=$ $9.2 \mathrm{~Hz}, 1 \mathrm{H}), 4.94(\mathrm{~d}, J=8.2 \mathrm{~Hz}, 1 \mathrm{H}), 4.81(\mathrm{~d}, J=11.6 \mathrm{~Hz}$, $1 \mathrm{H}), 4.76-4.68(\mathrm{~m}, 4 \mathrm{H}), 4.56(\mathrm{~d}, J=11.4 \mathrm{~Hz}, 1 \mathrm{H}), 4.52-4.49$ $(\mathrm{m}, 2 \mathrm{H}), 4.00(\mathrm{~d}, J=1.8 \mathrm{~Hz}, 1 \mathrm{H}, \mathrm{H} 5), 3.74-3.55(\mathrm{~m}, 6 \mathrm{H})$; ${ }^{13} \mathrm{C}$ NMR $\left(100 \mathrm{MHz}, \mathrm{CDCl}_{3}\right) \delta 163.8,161.4,147.0,138.6$, $138.1,138.0,137.8,128.7,128.62,128.60,128.58,128.4$ $128.1,128.02,127.95,127.9,127.69,127.67,127.6,127.5$, 127.24, 127.21, 84.6, 77.7, 77.3, 75.5, 74.7, 73.9, 73.7, 72.4, 69.2, 51.2; ${ }^{19} \mathrm{~F}$ NMR (376 MHz, $\left.\mathrm{CD}_{3} \mathrm{OD}\right) \delta-114.11$; HRMS $(\mathrm{m} / \mathrm{z}):[\mathrm{M}+\mathrm{H}]^{+}$calcd for 700.3195 ; found, 700.3187 .

3,4,5,7-Tetra-O-benzyl-1,2-dideoxy-1-[4-(3-fluorophenyl)-

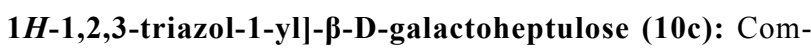
pound 9 (107 mg, $0.185 \mathrm{mmol})$ and copper(I) iodide (4 mg, $0.035 \mathrm{mmol})$ were dissolved in dry acetonitrile $(3 \mathrm{~mL})$ under nitrogen, triethylamine $(51 \mu \mathrm{L}(0.369 \mathrm{mmol})$ and 1-ethynyl-3fluorobenzene $(26 \mu \mathrm{L}, 0.221 \mathrm{mmol})$ were added, and the reaction was left at room temperature overnight. Upon completion, the reaction mixture was poured into ethyl acetate $(20 \mathrm{~mL})$ and washed with brine $(20 \mathrm{~mL})$. The brine was extracted with ethyl acetate $(2 \times 20 \mathrm{~mL})$, the organic phases pooled, dried with anhydrous sodium sulfate, and evaporated. The crude product was purified with column chromatography (heptane/ethyl acetate $2: 1)$ to give $10 \mathrm{c}(81 \mathrm{mg}, 63 \%)$ as a viscous clear oil. $[\alpha]_{\mathrm{D}}{ }^{20}-10$ (c 1.0, $\mathrm{CH}_{2} \mathrm{Cl}_{2}$ ); ${ }^{1} \mathrm{H}$ NMR (400 MHz, $\left.\mathrm{CDCl}_{3}\right) \delta 17.98(\mathrm{~s}, 1 \mathrm{H})$, 7.53-7.46 (m, 2H), 7.43-7.14 (m, 21H), 7.06-6.99 (m, 1H), $4.95(\mathrm{~d}, J=1.9 \mathrm{~Hz}, 1 \mathrm{H}), 4.92(\mathrm{~s}, 1 \mathrm{H}), 4.80(\mathrm{~d}, J=11.6 \mathrm{~Hz}$, $1 \mathrm{H}), 4.73(\mathrm{~d}, J=2.3 \mathrm{~Hz}, 1 \mathrm{H}), 4.71-4.67(\mathrm{~m}, 3 \mathrm{H}), 4.54(\mathrm{~d}, J=$ $11.6 \mathrm{~Hz}, 1 \mathrm{H}), 4.50-4.47$ (m, 2H), 3.99 (d, $J=1.8 \mathrm{~Hz}, 1 \mathrm{H}, \mathrm{H} 5)$, 3.73-3.52 (m, 6H); ${ }^{13} \mathrm{C} \mathrm{NMR}\left(100 \mathrm{MHz}, \mathrm{CDCl}_{3}\right) \delta 164.5$, $162.1,147.0,138.4,138.0,137.9,137.7,130.4,130.3,128.54$, $128.53,128.49,128.46,128.2,128.0,127.93,127.87,127.85$, $127.58,127.55,121,8,121.3,114.8,114.5,112.7,112.5,84.5$, 77.6, 77.2, 75.4, 74.8, 74.6, 73.7, 73.6, 72.2, 69.0, 51.1; ${ }^{19} \mathrm{~F}$ NMR (376 MHz, CD $\left.{ }_{3} \mathrm{OD}\right) \delta-112.85$; HRMS $(\mathrm{m} / \mathrm{z})$ : $[\mathrm{M}+\mathrm{H}]^{+}$calcd for 700.3185 ; found, 700.3187 .

3,4,5,7-Tetra-O-benzyl-1,2-dideoxy-1-[4-(2-fluorophenyl)-

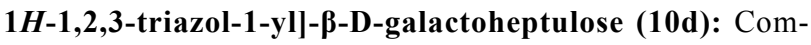
pound 9 (102 $\mathrm{mg}, 0.179 \mathrm{mmol})$ and copper(I) iodide (4 mg, $0.035 \mathrm{mmol})$ were dissolved in dry acetonitrile $(3 \mathrm{~mL})$ under nitrogen, triethylamine ( $49 \mu \mathrm{L}, 0.352 \mathrm{mmol})$ and 1-ethynyl-2fluorobenzene $(24 \mu \mathrm{L}, 0.211 \mathrm{mmol})$ were added, and the reaction was left at room temperature overnight. Upon completion, the reaction mixture was poured into ethyl acetate $(20 \mathrm{~mL})$ and washed with brine $(20 \mathrm{~mL})$. The brine was extracted with ethyl acetate $(2 \times 20 \mathrm{~mL})$, the organic phases pooled, dried with anhydrous sodium sulfate, and evaporated. The crude product was purified with column chromatography (heptane/ethyl acetate
$2: 1)$ to give $10 \mathrm{~d}$ (78 $\mathrm{mg}, 63 \%$ ) as a viscous lightly yellow oil. $[\alpha]_{\mathrm{D}}{ }^{20}-10\left(c 0.8, \mathrm{CH}_{2} \mathrm{Cl}_{2}\right) ;{ }^{1} \mathrm{H} \mathrm{NMR}\left(400 \mathrm{MHz}, \mathrm{CDCl}_{3}\right) \delta 8.32$ $\left(\mathrm{td}, J^{1}=7.6 \mathrm{~Hz}, 2.0 \mathrm{~Hz}, 1 \mathrm{H}\right), 8.18(\mathrm{~d}, J=3.9 \mathrm{~Hz}, 1 \mathrm{H})$, $7.45-7.09(\mathrm{~m}, 22 \mathrm{H}), 4.96(\mathrm{~d}, J=10.5 \mathrm{~Hz}, 1 \mathrm{H}), 4.93(\mathrm{~d}, J=$ $11.7 \mathrm{~Hz}, 1 \mathrm{H}), 4.81-4.59(\mathrm{~m}, 6 \mathrm{H}), 4.57$ (d, $J=11.5 \mathrm{~Hz}, 1 \mathrm{H})$, $4.49(\mathrm{~d}, J=11.7 \mathrm{~Hz}, 1 \mathrm{H}), 4.43(\mathrm{~d}, J=11.7 \mathrm{~Hz}, 1 \mathrm{H}), 3.98(\mathrm{~d}$, $J=0.8 \mathrm{~Hz}, 1 \mathrm{H}, \mathrm{H} 5), 3.74-3.65(\mathrm{~m}, 3 \mathrm{H}), 3.65-3.52(\mathrm{~m}, 3 \mathrm{H})$; ${ }^{13} \mathrm{C}$ NMR $\left(100 \mathrm{MHz}, \mathrm{CDCl}_{3}\right) \delta 158.0,141.1,138.5,138.02$, $137.96,137.8,129.1,129.0,128.53,128.46,128.4,128.3$, $128.2,128.0,127.9,127.8,127.7,127.6,127.4,124.8,124.6$, $124.5,115.8,115.6,84.5,77.7,77.2,75.4,74.9,74.5,73.6$, $73.5,73.2,72.2,69.0,51.1 ;{ }^{19} \mathrm{~F}$ NMR $\left(376 \mathrm{MHz}, \mathrm{CD}_{3} \mathrm{OD}\right) \delta$ -114.53 ; HRMS $(\mathrm{m} / \mathrm{z}):[\mathrm{M}+\mathrm{H}]^{+}$calcd for 700.3186 ; found, 700.3187 .

3,4,5,7-Tetra-O-benzyl-1,2-dideoxy-1-[4-(3,4-difluoro-

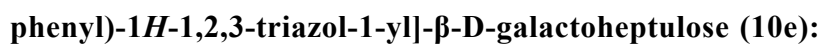
Compound 9 (103 mg, $0.176 \mathrm{mmol}$ ) and copper(I) iodide (4 mg, $0.035 \mathrm{mmol})$ were dissolved in dry acetonitrile $(3 \mathrm{~mL})$ under nitrogen, triethylamine $(49 \mu \mathrm{L}, 0.352 \mathrm{mmol})$ and 1-ethynyl-3,4difluorobenzene $(25 \mu \mathrm{L}, 0.211 \mathrm{mmol})$ were added, and the reaction was left at room temperature overnight. Upon completion, the reaction mixture was poured into ethyl acetate $(20 \mathrm{~mL})$ and washed with brine $(20 \mathrm{~mL})$. The brine was extracted with ethyl acetate $(2 \times 20 \mathrm{~mL})$, the organic phases pooled, dried with anhydrous sodium sulfate, and evaporated. The crude product was purified with column chromatography (heptane/ethyl acetate $2: 1)$ to give $10 \mathrm{e}(86 \mathrm{mg}, 68 \%)$ as a viscous lightly yellow oil. $[\alpha]_{\mathrm{D}}{ }^{20}-9\left(c 1.0, \mathrm{CH}_{2} \mathrm{Cl}_{2}\right) ;{ }^{1} \mathrm{H}$ NMR $\left(400 \mathrm{MHz}, \mathrm{CDCl}_{3}\right) \delta 7.93$ (s, 1H), 7.59-7.52 (m, 1H), 7.46-7.02 (m, 22H), $4.95(\mathrm{~d}, J=$ $2.9 \mathrm{~Hz}, 1 \mathrm{H}), 4.92(\mathrm{~d}, J=2.1 \mathrm{~Hz}, 1 \mathrm{H}), 4.80(\mathrm{~d}, J=11.6 \mathrm{~Hz}$, $1 \mathrm{H}), 4.75-4.66(\mathrm{~m}, 4 \mathrm{H}), 4.54(\mathrm{~d}, J=11.6 \mathrm{~Hz}, 1 \mathrm{H}), 4.51-4.47$ (m, 2H), 3.99 (d, $J=2.0 \mathrm{~Hz}, 1 \mathrm{H}, \mathrm{H} 5), 3.73-3.53(\mathrm{~m}, 6 \mathrm{H})$; ${ }^{13} \mathrm{C}$ NMR $\left(100 \mathrm{MHz}, \mathrm{CDCl}_{3}\right) \delta 138.4,137.93,137.86,137.7$, $128.6,128.54,128.50,128.46,128.2,127.99,127.96,127.9$, 127.6, 121.7, 121.5, 117.7, 117.5, 114.8, 114.6, 84.5, 77.5, 77.2, $75.4,74.7,74.6,73.7,73.6,72.3,69.1,51.2 ;{ }^{19} \mathrm{~F}$ NMR (376 MHz, $\left.\mathrm{CD}_{3} \mathrm{OD}\right) \delta-137.34,-137.40,-138.89,-138.95$; HRMS $(m / z):[\mathrm{M}+\mathrm{H}]^{+}$calcd for 718.3102 ; found, 718.3093 .

\section{3,4,5,7-Tetra-O-benzyl-1,2-dideoxy-1-[4-(3,5-difluoro-}

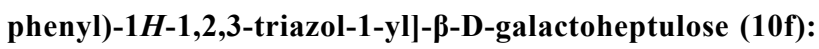
Compound 9 (106 mg, $0.183 \mathrm{mmol}$ ) and copper(I) iodide (4 mg, $0.035 \mathrm{mmol})$ were dissolved in dry acetonitrile $(3 \mathrm{~mL})$ under nitrogen, triethylamine $(51 \mu \mathrm{L}, 0.366 \mathrm{mmol})$ and 1-ethynyl-3,5difluorobenzene ( $26 \mu \mathrm{L}, 0.220 \mathrm{mmol}$ ) was added, and the reaction was left at room temperature overnight. Upon completion, the reaction mixture was poured into ethyl acetate $(20 \mathrm{~mL})$ and washed with brine $(20 \mathrm{~mL})$. The brine was extracted with ethyl acetate $(2 \times 20 \mathrm{~mL})$, the organic phases pooled, dried with anhydrous sodium sulfate, and evaporated. The crude product was 
purified with column chromatography (heptane/ethyl acetate $2: 1)$ to give $\mathbf{1 0 f}(88 \mathrm{mg}, 67 \%)$ as a viscous lightly yellow oil. $[\alpha]_{\mathrm{D}}{ }^{20}-12\left(c 1.1, \mathrm{CH}_{2} \mathrm{Cl}_{2}\right) ;{ }^{1} \mathrm{H} \mathrm{NMR}\left(400 \mathrm{MHz}, \mathrm{CDCl}_{3}\right) \delta 7.96$ (s, 1H), 7.44-7.17 (m, 22H), 6.78 (tt, $J=8.9 \mathrm{~Hz}, 2.3 \mathrm{~Hz}, 1 \mathrm{H})$, $4.95(\mathrm{~d}, J=4.0 \mathrm{~Hz}, 1 \mathrm{H}), 4.92(\mathrm{~d}, J=4.8 \mathrm{~Hz}, 1 \mathrm{H}), 4.80(\mathrm{~d}, J=$ $11.8 \mathrm{~Hz}, 1 \mathrm{H}), 4.75-4.66(\mathrm{~m}, 4 \mathrm{H}), 4.53(\mathrm{~d}, J=11.6 \mathrm{~Hz}, 1 \mathrm{H})$ $4.51-4.48(\mathrm{~m}, 2 \mathrm{H}), 3.98$ (d, $J=2.1 \mathrm{~Hz}, 1 \mathrm{H}, \mathrm{H} 5), 3.72-3.52(\mathrm{~m}$, $6 \mathrm{H}) ;{ }^{13} \mathrm{C} \mathrm{NMR}\left(100 \mathrm{MHz}, \mathrm{CDCl}_{3}\right) \delta 164.6,164.5,162.2,162.0$, $138.3,137.9,137.9,137.6,128.56,128.55,128.50,128.46$, $128.2,128.0,127.91,127.87,127.60,127.58,127.57,122.2$, 108.6, 108.3, 103.3, 103.0, 102.8, 84.5, 77.5, 77.2, 75.4, 74.7, 74.6, 73.7, 73.6, 72.2, 69.0, 51.2; ${ }^{19} \mathrm{~F}$ NMR (376 MHz, $\left.\mathrm{CD}_{3} \mathrm{OD}\right) \delta-109.45$; HRMS $(\mathrm{m} / \mathrm{z}):[\mathrm{M}+\mathrm{H}]^{+}$calcd for 718.3097; found, 718.3093.

3,4,5,7-Tetra-O-benzyl-1,2-dideoxy-1-[4-(2,4-difluoro-

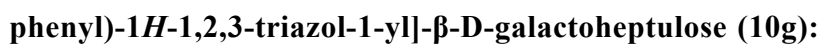
Compound 9 (150 mg, 0.259 mmol), 1-ethynyl-2,4-difluorobenzene (40 mg, $0.285 \mathrm{mmol})$, and copper(I) iodide (10 mg, $0.052 \mathrm{mmol})$ were dissolved in dry acetonitrile $(4 \mathrm{~mL})$ under nitrogen, triethylamine $(72 \mu \mathrm{L}, 0.518 \mathrm{mmol})$ was added, and the reaction left at $60{ }^{\circ} \mathrm{C}$ overnight. Upon completion, the reaction mixture was poured into ethyl acetate $(20 \mathrm{~mL})$ and washed with brine $(20 \mathrm{~mL})$. The brine was extracted with ethyl acetate $(2 \times 20 \mathrm{~mL})$, the organic phases pooled, dried with anhydrous sodium sulfate, and evaporated. The crude product was purified with column chromatography (heptane/ethyl acetate $3: 1$ ) to give $10 \mathrm{~g}(136 \mathrm{mg}, 73 \%)$ as a sticky clear solid. $[\alpha]_{\mathrm{D}}{ }^{20}-10$ (c 1.6, $\mathrm{CH}_{3} \mathrm{CN}$ ); ${ }^{1} \mathrm{H}$ NMR (400 MHz, $\mathrm{CDCl}_{3}$ ) $\delta 8.31-8.25(\mathrm{~m}, 2 \mathrm{H})$, $8.11(\mathrm{~d}, J=4.0 \mathrm{~Hz}, 1 \mathrm{H}), 7.45-7.17(\mathrm{~m}, 20 \mathrm{H}), 7.01(\mathrm{td}, J=$ $8.6 \mathrm{~Hz}, 2.3 \mathrm{~Hz}, 1 \mathrm{H}), 6.89-6.83(\mathrm{~m}, 1 \mathrm{H}), 4.98-4.90(\mathrm{~m}, 2 \mathrm{H})$, $4.81-4.69(\mathrm{~m}, 4 \mathrm{H}), 4.68-4.60(\mathrm{~m}, 1 \mathrm{H}), 4.56(\mathrm{~d}, J=11.3 \mathrm{~Hz}$, $1 \mathrm{H}), 4.51-4.42$ (m, 2H), 3.98 (s, 1H, H5), 3.72-3.54 (m, 6H); ${ }^{13} \mathrm{C}$ NMR $\left(100 \mathrm{MHz}, \mathrm{CDCl}_{3}\right) \delta 163.3,163.2,160.1,160.0$, $158.1,158.0,140.3,138.4,137.91,137.85,137.7,128.73$, $128.66,128.62,128.56,128.44,128.35,128.3,128.2,128.1$, $127.9,127.7,127.6,127.52,127.49,127.4,124.2,124.1,115.3$, $111.9,111.8,111.7,104.2,103.9,103.7,84.4,77.5,77.1,75.3$, 74.8, 74.4, 73.51, 73.47, 72.1, 69.0, 51.1; ${ }^{19} \mathrm{~F}$ NMR (376 MHz, $\left.\mathrm{CD}_{3} \mathrm{OD}\right) \delta-110.77,-110.96$; HRMS $(\mathrm{m} / \mathrm{z}):[\mathrm{M}+\mathrm{H}]^{+}$calcd for 718.3091 ; found, 718.9093 .

3,4,5,7-Tetra-O-benzyl-1,2-dideoxy-1-[4-(4-methylphenyl)-

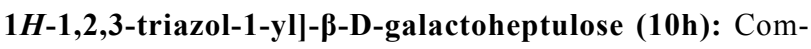
pound 9 (103 mg, $0.178 \mathrm{mmol}$ ) and copper(I) iodide (4 mg, $0.035 \mathrm{mmol})$ were dissolved in dry acetonitrile $(3 \mathrm{~mL})$ under nitrogen, triethylamine $(50 \mu \mathrm{L}, 0.356 \mathrm{mmol})$ and 4-ethynyltoluene $(27 \mu \mathrm{L}, 0.214 \mathrm{mmol})$ were added, and the reaction was left at $50{ }^{\circ} \mathrm{C}$ overnight. Upon completion, the reaction mixture was poured into ethyl acetate $(20 \mathrm{~mL})$ and washed with brine $(20 \mathrm{~mL})$. The brine was extracted with ethyl acetate
$(2 \times 20 \mathrm{~mL})$, the organic phases pooled, dried with anhydrous sodium sulfate, and evaporated. The crude product was purified with column chromatography (heptane/ethyl acetate $2: 1)$ to give 10h $(79 \mathrm{mg}, 64 \%)$ as viscous clear oil. $[\alpha]_{\mathrm{D}}{ }^{20}-12(c 0.7$, $\left.\mathrm{CH}_{2} \mathrm{Cl}_{2}\right) ;{ }^{1} \mathrm{H} \mathrm{NMR}\left(400 \mathrm{MHz}, \mathrm{CDCl}_{3}\right) \delta 7.95(\mathrm{~s}, 1 \mathrm{H})$, $7.69-7.64(\mathrm{~m}, 2 \mathrm{H}), 7.44-7.14(\mathrm{~m}, 22 \mathrm{H}), 4.96(\mathrm{~d}, J=5.1 \mathrm{~Hz}$, $1 \mathrm{H}), 4.93(\mathrm{~d}, J=4.3 \mathrm{~Hz}, 1 \mathrm{H}), 4.79(\mathrm{~d}, J=11.6 \mathrm{~Hz}, 1 \mathrm{H})$, $4.75-4.61(\mathrm{~m}, 4 \mathrm{H}), 4.56(\mathrm{~d}, J=11.6 \mathrm{~Hz}, 1 \mathrm{H}), 4.50-4.45(\mathrm{~m}$, $2 \mathrm{H}), 3.99$ (s, 1H, H5), 3.75-3.52 (m, 6H), $2.41(\mathrm{~s}, 3 \mathrm{H})$; ${ }^{13} \mathrm{C} \mathrm{NMR}\left(100 \mathrm{MHz}, \mathrm{CDCl}_{3}\right) \delta 138.5,138.0,137.9,137.7$, $137.6,129.4,128.54,128.52,128.49,128.3,128.1,128.0$, $127.9,127.8,127.6,127.5,125.7,121.0,84.5,77.8,77.2,75.4$ $74.9,74.6,73.7,73.5,72.2,69.0,51.1,21.3$; HRMS $(\mathrm{m} / \mathrm{z})$ : $[\mathrm{M}+\mathrm{H}]^{+}$calcd for 696.3450 ; found, 696.3437 .

3,4,5,7-Tetra-O-benzyl-1,2-dideoxy-1-[4-(3-methylphenyl)-

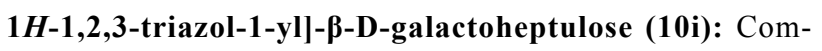
pound 9 (106 mg, $0.183 \mathrm{mmol}$ ) and copper(I) iodide (4 mg, $0.035 \mathrm{mmol})$ were dissolved in dry acetonitrile $(3 \mathrm{~mL})$ under nitrogen, triethylamine $(50 \mu \mathrm{L}, 0.366 \mathrm{mmol})$ and 3-ethynyltoluene $(27 \mu \mathrm{L}, 0.214 \mathrm{mmol})$ were added, and the reaction was left at $50{ }^{\circ} \mathrm{C}$ overnight. Upon completion, the reaction mixture was poured into ethyl acetate $(20 \mathrm{~mL})$ and washed with brine $(20 \mathrm{~mL})$. The brine was extracted with ethyl acetate $(2 \times 20 \mathrm{~mL})$, the organic phases pooled, dried with anhydrous sodium sulfate, and evaporated. The crude product was purified with column chromatography (heptane/ethyl acetate 2:1) to give $10 \mathbf{i}(83 \mathrm{mg}, 65 \%)$ as a viscous lightly yellow oil. $[\alpha]_{\mathrm{D}}{ }^{20}-7.8(\mathrm{c}$ 0.8, $\mathrm{CH}_{2} \mathrm{Cl}_{2}$ ); ${ }^{1} \mathrm{H} \mathrm{NMR}\left(400 \mathrm{MHz}, \mathrm{CDCl}_{3}\right) \delta 7.97(\mathrm{~s}, 1 \mathrm{H}), 7.69$ (s, 1H), 7.52 (d, $J=7.63 \mathrm{~Hz}, 1 \mathrm{H}), 7.44-7.11(\mathrm{~m}, 22 \mathrm{H}), 4.96$ (d, $J=3.2 \mathrm{~Hz}, 1 \mathrm{H}), 4.93(\mathrm{~d}, J=1.6 \mathrm{~Hz}, 1 \mathrm{H}), 4.79(\mathrm{~d}, J=11.7 \mathrm{~Hz}$, $1 \mathrm{H}), 4.75-4.59(\mathrm{~m}, 4 \mathrm{H}), 4.56(\mathrm{~d}, J=11.7 \mathrm{~Hz}, 1 \mathrm{H}), 4.50-4.45$ $(\mathrm{m}, 2 \mathrm{H}), 3.98(\mathrm{~d}, J=1.1 \mathrm{~Hz}, 1 \mathrm{H}, \mathrm{H} 5), 3.76-3.52(\mathrm{~m}, 6 \mathrm{H}), 2.40$ $(\mathrm{s}, 3 \mathrm{H}) ;{ }^{13} \mathrm{C}$ NMR $\left(100 \mathrm{MHz}, \mathrm{CDCl}_{3}\right) \delta 147.7,138.5,138.4$, $138.0,137.9,137.7,130.7,128.7,128.54,128.52,128.48$, $128.0,127.9,127.8,127.57,127.55,127.5,126.5,122.9,121.4$, 84.5, 77.7, 77.2, 75.4, 74.9, 74.5, 73.7, 73.5, 72.2, 69.0, 51.1, 21.5; HRMS $(\mathrm{m} / \mathrm{z}):[\mathrm{M}+\mathrm{H}]^{+}$calcd for 696.3442 ; found, 696.3437.

\section{3,4,5,7-Tetra-O-benzyl-1,2-dideoxy-1-[4-(4-trifluo-}

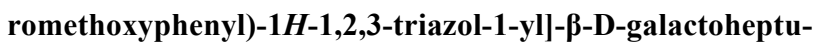
lose (10j): Compound 9 (100 mg, $0.173 \mathrm{mmol})$, 4-(trifluoromethoxy)ethynylbenzene ( $34 \mathrm{mg}, 0.181 \mathrm{mmol}$ ), and copper(I) iodide ( $7 \mathrm{mg}, 0.035 \mathrm{mmol}$ ) were dissolved in dry acetonitrile (3 mL) under nitrogen, $(50 \mu \mathrm{L}, 0.356 \mathrm{mmol})$ triethylamine was added, and the reaction left at room temperature overnight. Upon completion, the reaction mixture was poured into ethyl acetate $(20 \mathrm{~mL})$ and washed with brine $(20 \mathrm{~mL})$. The brine was extracted with ethyl acetate $(2 \times 20 \mathrm{~mL})$, the organic phases pooled, dried with anhydrous sodium sulfate, and evaporated. 
The crude product was purified with column chromatography (heptane/ethyl acetate $2: 1)$ to give $\mathbf{1 0 j}$ (103 $\mathrm{mg}, 78 \%$ ) as a clear solid. $[\alpha]_{\mathrm{D}}{ }^{20}-19\left(c=0.8, \mathrm{CHCl}_{3}\right) ;{ }^{1} \mathrm{H}$ NMR $\left(400 \mathrm{MHz}, \mathrm{CDCl}_{3}\right)$ $\delta 8.00(\mathrm{~s}, 1 \mathrm{H}), 7.76-7.71(\mathrm{~m}, 2 \mathrm{H}), 7.44-7.15(\mathrm{~m}, 22 \mathrm{H})$, $4.98-4.91(\mathrm{~m}, 2 \mathrm{H}), 4.81(\mathrm{~d}, J=11.8 \mathrm{~Hz}, 1 \mathrm{H}), 4.77-4.66(\mathrm{~m}$, $4 \mathrm{H}), 4.55(\mathrm{~d}, J=11.8 \mathrm{~Hz}, 1 \mathrm{H}), 4.52-4.49(\mathrm{~m}, 2 \mathrm{H}), 4.00(\mathrm{~d}, J=$ $2.3 \mathrm{~Hz}, 1 \mathrm{H}, \mathrm{H} 5), 3.75-3.55(\mathrm{~m}, 6 \mathrm{H}) ;{ }^{13} \mathrm{C} \mathrm{NMR}(100 \mathrm{MHz}$, $\left.\mathrm{CDCl}_{3}\right) \delta 148.7,146.5,138.4,138.0,137.9,137.7,129.7$, $128.56,128.54,128.51,128.48,128.4,128.2,128.0,127.93$, $127.87,127.8,127.59,127.55,127.5,127.1,121.8,121.6$, 121.4, 84.5, 77.6, 77.2, 75.4, 74.7, 74.6, 73.8, 73.6, 72.3, 69.2, 51.1; ${ }^{19} \mathrm{~F}$ NMR $\left(376 \mathrm{MHz}, \mathrm{CD}_{3} \mathrm{OD}\right) \delta-57.78$; HRMS $(\mathrm{m} / \mathrm{z})$ : $[\mathrm{M}+\mathrm{H}]^{+}$calcd for 766.3108 ; found, 766.3104 .

3,4,5,7-Tetra-O-benzyl-1,2-dideoxy-1-[4-(4-trifluoromethylphenyl]-1H-1,2,3-triazol-1-yl)- $\beta$-D-galactoheptulose (10k): Compound 9 (100 mg, $0.178 \mathrm{mmol})$, 4-(trifluoromethane)ethynylbenzene (31 mg, $0.181 \mathrm{mmol}$ ), and copper(I) iodide $(7 \mathrm{mg}, 0.035 \mathrm{mmol})$ were dissolved in dry acetonitrile ( $3 \mathrm{~mL})$ under nitrogen, triethylamine $(50 \mu \mathrm{L}, 0.356 \mathrm{mmol})$ was added, and the reaction left at room temperature overnight. Upon completion, the reaction mixture was poured into ethyl acetate $(20 \mathrm{~mL})$ and washed with brine $(20 \mathrm{~mL})$. The brine was extracted with ethyl acetate $(2 \times 20 \mathrm{~mL})$, the organic phases pooled, dried with anhydrous sodium sulfate, and evaporated. The crude product was purified with column chromatography (heptane/ethyl acetate 2:1) to give 10k (94 mg, 73\%) as a white solid. $[\alpha]_{\mathrm{D}}{ }^{20}-22\left(c\right.$ 1.0, $\left.\mathrm{CHCl}_{3}\right) ;{ }^{1} \mathrm{H} \mathrm{NMR}\left(400 \mathrm{MHz}, \mathrm{CDCl}_{3}\right) \delta$ $8.08(\mathrm{~s}, 1 \mathrm{H}), 7.85-7.80(\mathrm{~m}, 2 \mathrm{H}), 7.65-7.60(\mathrm{~m}, 2 \mathrm{H}), 7.46-7.15$ (m, 20H), $4.98(\mathrm{~d}, J=7.1 \mathrm{~Hz}, 1 \mathrm{H}), 4.95(\mathrm{~d}, J=6.1 \mathrm{~Hz}, 1 \mathrm{H})$, $4.82(\mathrm{~d}, J=11.6 \mathrm{~Hz}, 1 \mathrm{H}), 4.77-4.69(\mathrm{~m}, 4 \mathrm{H}), 4.56(\mathrm{~d}, J=11.4$ $\mathrm{Hz}, 1 \mathrm{H}), 4.54-4.51(\mathrm{~m}, 2 \mathrm{H}), 4.02(\mathrm{~d}, J=2.4 \mathrm{~Hz}, 1 \mathrm{H}, \mathrm{H} 5)$, $3.78-3.56(\mathrm{~m}, 6 \mathrm{H}) ;{ }^{13} \mathrm{C} \mathrm{NMR}\left(100 \mathrm{MHz}, \mathrm{CDCl}_{3}\right) \delta 146.3$, $138.4,138.0,137.9,137.7,134.3,132.9,129.8,129.4,129.1$, $128.7,128.58,128.56,128.53,128.49,128.4,128.02,127.96$, $127.9,127.84,127.75,127.6,127.5,125.8,122.2,84.5,77.5$, $77.2,75.5,74.72,74.66,73.8,73.6,72.3,69.2,51.2 ;{ }^{19} \mathrm{~F}$ NMR (376 MHz, $\left.\mathrm{CD}_{3} \mathrm{OD}\right) \delta-62.48$; HRMS $(\mathrm{m} / \mathrm{z}):[\mathrm{M}+\mathrm{H}]^{+}$calcd for 750.3162 ; found, 750.3155 .

\section{3,4,5,7-Tetra- $O$-benzyl-1,2-dideoxy-1-(4-naphth-1-yl- $1 \mathrm{H}$ -} 1,2,3-triazol-1-yl)- $\boldsymbol{\beta}$-D-galactoheptulose (101): Compound 9 (228 mg, $0.393 \mathrm{mmol})$, 1-ethynylnaphtalene $(63 \mathrm{mg}$, $0.413 \mathrm{mmol}$ ), and copper(I) iodide (15 $\mathrm{mg}, 0.079 \mathrm{mmol})$ were dissolved in dry acetonitrile $(4 \mathrm{~mL})$ under nitrogen, triethylamine $(110 \mu \mathrm{L}, 0.786 \mathrm{mmol})$ was added, and the reaction left at $60{ }^{\circ} \mathrm{C}$ overnight. Upon completion, the reaction mixture was poured into ethyl acetate $(20 \mathrm{~mL})$ and washed with brine $(20 \mathrm{~mL})$. The brine was extracted with ethyl acetate $(2 \times 20 \mathrm{~mL})$, the organic phases pooled, dried with anhydrous sodium sulfate, and evaporated. The crude product was purified with column chromatography (heptane/ethyl acetate $3: 1)$ to give $101(120 \mathrm{mg}, 42 \%)$ as a sticky clear solid. $[\alpha]_{\mathrm{D}}{ }^{20}-11(c 1.1$, $\left.\mathrm{CHCl}_{3}\right) ;{ }^{1} \mathrm{H} \mathrm{NMR}\left(400 \mathrm{MHz}, \mathrm{CDCl}_{3}\right) \delta 8.40(\mathrm{~d}, J=8.5 \mathrm{~Hz}$, $1 \mathrm{H}), 8.04(\mathrm{~s}, 1 \mathrm{H}), 7.94-7.88(\mathrm{~m}, 2 \mathrm{H}), 7.66(\mathrm{dd}, J=7.2 \mathrm{~Hz}$, $1.1 \mathrm{~Hz}, 1 \mathrm{H}), 7.54-7.12(\mathrm{~m}, 23 \mathrm{H}), 5.00(\mathrm{~d}, J=10.9 \mathrm{~Hz}, 1 \mathrm{H})$, $4.94(\mathrm{~d}, J=11.8 \mathrm{~Hz}, 1 \mathrm{H}), 4.85-4.77(\mathrm{~m}, 3 \mathrm{H}), 4.76-4.68(\mathrm{~m}$, $3 \mathrm{H}), 4.59$ (d, $J=11.8 \mathrm{~Hz}, 1 \mathrm{H}), 4.47-4.44(\mathrm{~m}, 2 \mathrm{H}), 4.01(\mathrm{~s}, 1 \mathrm{H}$, $\mathrm{H} 5), 3.77-3.69(\mathrm{~m}, 3 \mathrm{H}), 3.68-3.56(\mathrm{~m}, 3 \mathrm{H}) ;{ }^{13} \mathrm{C} \mathrm{NMR}$ $\left(100 \mathrm{MHz}, \mathrm{CDCl}_{3}\right) \delta 146.6,138.4,138.04,137.95,137.7$, $133.9,131.2,128.63,128.55,128.52,128.46,128.4,128.3$, $128.2,128.0,127.9,127.8,127.61,127.55,127.2,126.5,125.9$, $125.6,125.4,124.5,84.6,77.7,77.2,75.4,74.9,74.6,73.8$, 73.6, 72.3, 69.0, 51.1; HRMS $(\mathrm{m} / \mathrm{z}):[\mathrm{M}+\mathrm{H}]^{+}$calcd for 732.3442 ; found, 732.3437 .

3,4,5,7-Tetra-O-benzyl-1,2-dideoxy-1-[4-(4-biphenyl)- $1 \mathrm{H}$ 1,2,3-triazol-1-yl]- $\beta$-D-galactoheptulose (10m): Compound 9 (103 mg, $0.178 \mathrm{mmol}$ ), 4-ethynylbiphenyl (38 mg (0.213 mmol), and copper(I) iodide (4 $\mathrm{mg}, 0.035 \mathrm{mmol})$ were dissolved in dry acetonitrile $(3 \mathrm{~mL})$ under nitrogen, triethylamine (50 $\mu \mathrm{L}, 0.356 \mathrm{mmol}$ ) was added, and the reaction left at room temperature overnight. Upon completion, the reaction mixture was poured into ethyl acetate $(20 \mathrm{~mL})$ and washed with brine $(20 \mathrm{~mL})$. The brine was extracted with ethyl acetate $(2 \times 20 \mathrm{~mL})$, the organic phases pooled, dried with anhydrous sodium sulfate, and evaporated. The crude product was purified with column chromatography (heptane/ethyl acetate $2: 1$ ) to give $10 \mathrm{~m}(72 \mathrm{mg}, 53 \%)$ as a white solid. $[\alpha]_{\mathrm{D}}{ }^{20}-45\left(c 1.0, \mathrm{CH}_{2} \mathrm{Cl}_{2}\right)$; ${ }^{1} \mathrm{H}$ NMR (400 MHz, $\left.\mathrm{CDCl}_{3}\right) \delta 8.03(\mathrm{~s}, 1 \mathrm{H}), 7.86-7.80(\mathrm{~m} .2 \mathrm{H})$, 7.69-7.58 (m, 4H), 7.53-7.46 (m, 2H), 7.44-7.15 (m, 21H), $4.97(\mathrm{~d}, J=7.1 \mathrm{~Hz}, 1 \mathrm{H}), 4.94(\mathrm{~d}, J=6.1 \mathrm{~Hz}, 1 \mathrm{H}), 4.80(\mathrm{~d}, J=$ $11.7 \mathrm{~Hz}, 1 \mathrm{H}), 4.76-4.69(\mathrm{~m}, 4 \mathrm{H}), 4.56(\mathrm{~d}, J=11.5 \mathrm{~Hz}, 1 \mathrm{H})$, $4.52-4.48(\mathrm{~m}, 2 \mathrm{H}), 4.00(\mathrm{~d}, J=1.9 \mathrm{~Hz}, 1 \mathrm{H}, \mathrm{H} 5), 3.77-3.55(\mathrm{~m}$, $6 \mathrm{H}) ;{ }^{13} \mathrm{C} \mathrm{NMR}\left(100 \mathrm{MHz}, \mathrm{CDCl}_{3}\right) \delta 147.4,140.8,140.6,138.5$, $138.0,137.9,137.7,129.9,128.8,128.54,128.53,128.50$, $128.3,128.0,127.90,127.85,127.58,127.55,127.51,127.48$, $127.4,127.0,126.11,121.4,84.5,77.7,772,75.4,74.8,74.6$, 73.7, 73.6, 72.2, 69.1, 51.1; HRMS $(\mathrm{m} / \mathrm{z}):[\mathrm{M}+\mathrm{H}]^{+}$calcd for 758.3600 ; found, 758.3594 .

\section{3,4,5,7-Tetra-O-benzyl-1,2-dideoxy-1-(4-napht-2-yl- $1 \mathrm{H}$ -} 1,2,3-triazol-1-yl)- $\boldsymbol{\beta}$-D-galactoheptulose (10n): Compound 9 (150 mg, $0.259 \mathrm{mmol}$ ), 2-ethynylnaphthalene (43 mg, $0.285 \mathrm{mmol}$ ), and copper(I) iodide (10 $\mathrm{mg}, 0.052 \mathrm{mmol})$ were dissolved in dry acetonitrile $(4 \mathrm{~mL})$ under nitrogen, triethylamine ( $72 \mu \mathrm{L}, 0.518 \mathrm{mmol}$ ) was added, and the reaction left at $60{ }^{\circ} \mathrm{C}$ overnight. Upon completion, the reaction mixture was poured into ethyl acetate $(20 \mathrm{~mL})$ and washed with brine $(20 \mathrm{~mL})$. The brine was extracted with ethyl acetate $(2 \times 20 \mathrm{~mL})$, the organic phases pooled, dried with anhydrous sodium sulfate, and evaporated. The crude product was purified 
with column chromatography (heptane/ethyl acetate $3: 1$ ) to give 10n (143 mg of product with a yield of, $75 \%$ ) as a sticky clear solid. $[\alpha]_{\mathrm{D}}{ }^{20}-25\left(c\right.$ 1.6, $\left.\mathrm{CH}_{3} \mathrm{CN}\right) ;{ }^{1} \mathrm{H}$ NMR $\left(400 \mathrm{MHz}, \mathrm{CDCl}_{3}\right)$ $\delta 8.33(\mathrm{~s}, 1 \mathrm{H}), 8.11(\mathrm{~s}, 1 \mathrm{H}), 7.90-7.84(\mathrm{~m}, 4 \mathrm{H}), 7.55-7.48(\mathrm{~m}$, 2H), 7.47-7.27 (m, 15H), 7.26-7.21 (m, 2H), 7.18-7.13 (m, $3 \mathrm{H}), 4.98(\mathrm{~d}, J=3.6 \mathrm{~Hz}, 1 \mathrm{H}), 4.95(\mathrm{~d}, J=4.7 \mathrm{~Hz}, 1 \mathrm{H})$, $4.83-4.71(\mathrm{~m}, 5 \mathrm{H}), 4.57(\mathrm{~d}, J=11.7 \mathrm{~Hz}, 1 \mathrm{H}), 4.51(\mathrm{~s}, 2 \mathrm{H}), 4.01$ $(\mathrm{d}, J=0.9 \mathrm{~Hz}, 1 \mathrm{H}, \mathrm{H} 5), 3.75-3.58(\mathrm{~m}, 6 \mathrm{H}) ;{ }^{13} \mathrm{C}$ NMR $\left(100 \mathrm{MHz} \mathrm{CDCl}_{3}\right) \delta 147.7,138.5,138.0,137.9,137.8,133.6$, $133.1,128.7,128.54,128.49,128.34,128.28,128.2,128.0$, $127.9,127.8,127.7,127.59,127.57,127.5,126.3,126.0,124.4$, 124.0, 121.7, 84.6, 77.8, 77.2, 75.4, 74.9, 74.6, 73.7, 73.6, 73.3, 72.3, 69.1, 51.2; HRMS $(\mathrm{m} / \mathrm{z}):[\mathrm{M}+\mathrm{H}]^{+}$calcd for 732.3443 ; found, 732.3443 .

\section{Fluorescence polarization experiments}

Human galectin-1 [36] and galectin-3 [37] were expressed and purified as earlier described. Fluorescence polarization experiments were performed on a PheraStarFS plate reader with software PHERAstar Mars version 2.10 R3 (BMG, Offenburg, Germany). Specific experimental conditions were a galectin-1 concentration of $0.5 \mu \mathrm{M}$ together with the fluorescent probe (3,3'-dideoxy-3-[4-(fluorescein-5-ylcarbonylaminomethyl)- $1 \mathrm{H}$ 1,2,3-triazol-1-yl]-3' -(3,5-dimethoxybenzamido)-1,1'sulfanediyl-di- $\beta$-D-galactopyranoside [36]) concentration of $20 \mathrm{nM}$ and a galectin-3 concentration of $0.2 \mu \mathrm{M}$ together with the fluorescent probe (3,3'-dideoxy-3-[4-(fluorescein-5-ylcarbonylaminomethyl)-1 $H$-1,2,3-triazol-1-yl]-3'-(3,5-dimethoxybenzamido)-1,1'-sulfanediyl-di- $\beta$-D-galactopyranoside) concentration of $20 \mathrm{nM}$, respectively. Inhibitors were dissolved in dimethyl sulfoxide (analytical grade) to a concentration of $20 \mathrm{mM}$, diluted with PBS to 3-6 different concentrations, and tested in duplicate twice for galectin affinity using a competitive fluorescence polarization assay as earlier described [33]. The highest inhibitor concentrations tested were $1.5 \mathrm{mM}$ due to solubility limitations at higher concentration. Dissociation constants average and SEM were calculated from two to eight single point measurements showing between $20-80 \%$ inhibition.

\section{Molecular modelling}

Molecular dynamics simulations were performed with the OPLS3 force field in Desmond Desmond (Schrödinger Release 2017-3: Desmond Molecular Dynamics System, D. E. Shaw Research, New York, NY, 2017. Maestro-Desmond Interoperability Tools, Schrödinger, New York, NY, 2017) using default settings except for the length of the simulation and the use of light harmonic constraints $(1 \mathrm{kcal} / \mathrm{mol} / \AA)$ on all stranded backbone atoms and on the galactose $\mathrm{O} 4$ atom. Non-minimized conformations of $\mathbf{1 b}$ were positioned to replace lactose in the binding site of galectin-1 (pdb id 1GWZ) with the galactose ring in an orientation identical to that in lactose and with the phenyl triazole rings extending into bulk between the Trp68Gly69-Thr70 and His52 was subjected to a 200 ns molecular dynamics simulation. Non-minimized conformations of $\mathbf{1} \mathbf{b}$ were positioned to replace lactose in the binding site of galectin-3 (pdb id 1KJL) with the galactose ring in an orientation identical to that in $\mathrm{N}$-acetyllactosamine and with the phenyl triazole rings extending into bulk between the Trp68-Gly69-Thr70 and His52 was subjected to a $200 \mathrm{~ns}$ molecular dynamics simulation. Energy minimizations of four different MD snapshots of $\mathbf{1 b}$ in complex with galectin-1 and with galectin-3 were performed with the OPLS3 force field in MacroModel (performed with the OPLS3 force field in MacroModel (Schrödinger Release 20173: MacroModel, Schrödinger, LLC, New York, NY, 2017) using default settings.

\section{Supporting Information}

\section{Supporting Information File 1}

Copies of ${ }^{1} \mathrm{H}$ NMR and ${ }^{13} \mathrm{C}$ NMR spectra for compounds 1-10.

[https://www.beilstein-journals.org/bjoc/content/ supplementary/1860-5397-15-102-S1.pdf]

\section{Acknowledgements}

The authors thank Sofia Essén for assistance with HRMS and UPLC/MS-measurements and Barbro Kahl-Knutson for the fluorescence polarization assay. The Swedish Research Council (Grant No. 621-2012-2978 and 621-2016-03667), the Royal Physiographic Society, Lund, Sweden, a project grant awarded by the Knut and Alice Wallenberg Foundation (KAW 2013.0022), and Galecto Biotech AB, Sweden.

\section{ORCID ${ }^{\circledR}$ iDs}

Alexander Dahlqvist - https://orcid.org/0000-0002-1767-2503

Axel Furevi - https://orcid.org/0000-0002-0904-9498

Niklas Warlin - https://orcid.org/0000-0001-8041-370X

Hakon Leffler - https://orcid.org/0000-0003-4482-8945

Ulf J. Nilsson - https://orcid.org/0000-0001-5815-9522

\section{References}

1. Barondes, S. H.; Castronovo, V.; Cooper, D. N. W.; Cummings, R. D.; Drickamer, K.; Felzi, T.; Gitt, M. A.; Hirabayashi, J.; Hughes, C.; Kasai, K.-i.; Leffler, H.; Liu, F.-T.; Lotan, R.; Mercurio, A. M.; Monsigny, M.; Pillai, S.; Poirer, F.; Raz, A.; Rigby, P. W. J.; Rini, J. M.; Wang, J. L. Cell 1994, 76, 597-598. doi:10.1016/0092-8674(94)90498-7

2. Barondes, S. H.; Cooper, D. N. W.; Gitt, M. A.; Leffler, H. J. Biol. Chem. 1994, 269, 20807-20810.

3. Johannes, L.; Jacob, R.; Leffler, H. J. Cell Sci. 2018, 131, jcs208884. doi:10.1242/jcs.208884 
4. Leffler, H.; Carlsson, S.; Hedlund, M.; Qian, Y.; Poirier, F. Glycoconjugate J. 2002, 19, 433-440. doi:10.1023/b:glyc.0000014072.34840.04

5. Song, X.; Xia, B.; Stowell, S. R.; Lasanajak, Y.; Smith, D. F.; Cummings, R. D. Chem. Biol. 2009, 16, 36-47. doi:10.1016/j.chembiol.2008.11.004

6. Delaine, T.; Collins, P.; MacKinnon, A.; Sharma, G.; Stegmayr, J.; Rajput, V. K.; Mandal, S.; Cumpstey, I.; Larumbe, A.; Salameh, B. A.; Kahl-Knutsson, B.; van Hattum, H.; van Scherpenzeel, M.; Pieters, R. J.; Sethi, T.; Schambye, H.; Oredsson, S.; Leffler, H.; Blanchard, H.; Nilsson, U. J. ChemBioChem 2016, 17, 1759-1770. doi:10.1002/cbic.201600285

7. Priglinger, C. S.; Szober, C. M.; Priglinger, S. G.; Merl, J.; Euler, K. N.; Kernt, M.; Gondi, G.; Behler, J.; Geerlof, A.; Kampik, A.; Ueffing, M.; Hauck, S. M. PLoS One 2013, 8, e70011. doi:10.1371/journal.pone.0070011

8. Markowska, A. I.; Jefferies, K. C.; Panjwani, N. J. Biol. Chem. 2011, 286, 29913-29921. doi:10.1074/jbc.m111.226423

9. Dange, M. C.; Bhonsle, H. S.; Godbole, R. K.; More, S. K.; Bane, S. M.; Kulkarni, M. J.; Kalraiya, R. D. Mol. BioSyst. 2017, 13, 2303-2309. doi:10.1039/c7mb00260b

10. MacKinnon, A. C.; Gibbons, M. A.; Farnworth, S. L.; Leffler, H.; Nilsson, U. J.; Delaine, T.; Simpson, A. J.; Forbes, S. J.; Hirani, N.; Gauldie, J.; Sethi, T. Am. J. Respir. Crit. Care Med. 2012, 185, 537-546. doi:10.1164/rccm.201106-0965oc

11. Chen, W.-S.; Cao, Z.; Sugaya, S.; Lopez, M. J.; Sendra, V. G.; Laver, N.; Leffler, H.; Nilsson, U. J.; Fu, J.; Song, J.; Xia, L.; Hamrah, P.; Panjwani, N. Nat. Commun. 2016, 7, No. 11302. doi:10.1038/ncomms 11302

12. Rabinovich, G. A.; Rubinstein, N.; Toscano, M. A. Biochim. Biophys. Acta, Gen. Subj. 2002, 1572, 274-284. doi:10.1016/s0304-4165(02)00314-8

13. Danguy, A.; Camby, I.; Kiss, R. Biochim. Biophys. Acta, Gen. Subj. 2002, 1572, 285-293. doi:10.1016/s0304-4165(02)00315-x

14. Stannard, K. A.; Collins, P. M.; Ito, K.; Sullivan, E. M.; Scott, S. A.; Gabutero, E.; Darren Grice, I.; Low, P.; Nilsson, U. J.; Leffler, H.; Blanchard, H.; Ralph, S. J. Cancer Lett. 2010, 299, 95-110. doi:10.1016/j.canlet.2010.08.005

15. Sörme, P.; Arnoux, P.; Kahl-Knutsson, B.; Leffler, H.; Rini, J. M.; Nilsson, U. J. J. Am. Chem. Soc. 2005, 127, 1737-1743. doi:10.1021/ja043475p

16. Salameh, B. A.; Cumpstey, I.; Sundin, A.; Leffler, H.; Nilsson, U. J. Bioorg. Med. Chem. 2010, 18, 5367-5378. doi:10.1016/j.bmc.2010.05.040

17. Salameh, B. A.; Leffler, H.; Nilsson, U. J. Bioorg. Med. Chem. Lett. 2005, 15, 3344-3346. doi:10.1016/j.bmcl.2005.05.084

18. Salomonsson, E.; Carlsson, M. C.; Osla, V.; Hendus-Altenburger, R.; Kahl-Knutson, B.; Öberg, C. T.; Sundin, A.; Nilsson, R.; Nordberg-Karlsson, E.; Nilsson, U. J.; Karlsson, A.; Rini, J. M.; Leffler, H. J. Biol. Chem. 2010, 285, 35079-35091. doi:10.1074/jbc.m109.098160

19. Cumpstey, I.; Sundin, A.; Leffler, H.; Nilsson, U. J. Angew. Chem., Int. Ed. 2005, 44, 5110-5112. doi:10.1002/anie.200500627

20. López-Lucendo, M. F.; Solís, D.; André, S.; Hirabayashi, J.; Kasai, K.-i.; Kaltner, H.; Gabius, H.-J.; Romero, A. J. Mol. Biol. 2004, 343, 957-970. doi:10.1016/j.jmb.2004.08.078

21. Seetharaman, J.; Kanigsberg, A.; Slaaby, R.; Leffler, H.; Barondes, S. H.; Rini, J. M. J. Biol. Chem. 1998, 273, 13047-13052. doi:10.1074/jbc.273.21.13047
22. Giguère, D.; Bonin, M.-A.; Cloutier, P.; Patnam, R.; St-Pierre, C.; Sato, S.; Roy, R. Bioorg. Med. Chem. 2008, 16, 7811-7823. doi:10.1016/j.bmc.2008.06.044

23. Giguère, D.; André, S.; Bonin, M.-A.; Bellefleur, M.-A.; Provencal, A.; Cloutier, P.; Pucci, B.; Roy, R.; Gabius, H.-J. Bioorg. Med. Chem. 2011, 19, 3280-3287. doi:10.1016/j.bmc.2011.03.022

24. Zetterberg, F. R.; Peterson, K.; Johnsson, R. E.; Brimert, T.; Håkansson, M.; Logan, D. T.; Leffler, H.; Nilsson, U. J. ChemMedChem 2018, 13, 133-137. doi:10.1002/cmdc.201700744

25. Waschke, D.; Thimm, J.; Thiem, J. Org. Lett. 2011, 13, 3628-3631. doi:10.1021/ol2012764

26. Leshch, Y.; Jacobsen, A.; Thimm, J.; Thiem, J. Org. Lett. 2013, 15, 4948-4951. doi:10.1021/ol4021699

27. Ceccon, J.; Danoun, G.; Greene, A. E.; Poisson, J.-F. Org. Biomol. Chem. 2009, 7, 2029-2031. doi:10.1039/b901488h

28. Clark, J. S.; Kettle, J. G. Tetrahedron 1999, 55, 8231-8248. doi:10.1016/s0040-4020(99)00303-8

29. Clark, J. S.; Kettle, J. G. Tetrahedron Lett. 1997, 38, 123-126. doi:10.1016/s0040-4039(96)02232-0

30. Pasto, D. J.; Cumbo, C. C. J. Am. Chem. Soc. 1964, 86, 4343-4350. doi:10.1021/ja01074a022

31. RajanBabu, T. V.; Reddy, G. S. J. Org. Chem. 1986, 51, 5458-5461. doi:10.1021/jo00376a088

32. Tornøe, C. W.; Christensen, C.; Meldal, M. J. Org. Chem. 2002, 67, 3057-3064. doi:10.1021/jo011148j

33. Sörme, P.; Kahl-Knutsson, B.; Huflejt, M.; Nilsson, U. J.; Leffler, H. Anal. Biochem. 2004, 334, 36-47. doi:10.1016/j.ab.2004.06.042

34. Peterson, K.; Collins, P. M.; Huang, X.; Kahl-Knutsson, B.; Essén, S.; Zetterberg, F. R.; Oredsson, S.; Leffler, H.; Blanchard, H.; Nilsson, U. J. RSC Adv. 2018, 8, 24913-24922. doi:10.1039/c8ra04389b

35. Cumpstey, I.; Carlsson, S.; Leffler, H.; Nilsson, U. J. Org. Biomol. Chem. 2005, 3, 1922-1932. doi:10.1039/b502354h

36. Salomonsson, E.; Larumbe, A.; Tejler, J.; Tullberg, E.; Rydberg, H.; Sundin, A.; Khabut, A.; Frejd, T.; Lobsanov, Y. D.; Rini, J. M.; Nilsson, U. J.; Leffler, H. Biochemistry 2010, 49, 9518-9532. doi:10.1021/bi1009584

37. Massa, S. M.; Cooper, D. N. W.; Leffler, H.; Barondes, S. H. Biochemistry 1993, 32, 260-267. doi:10.1021/bi00052a033

\section{License and Terms}

This is an Open Access article under the terms of the Creative Commons Attribution License (http://creativecommons.org/licenses/by/4.0). Please note that the reuse, redistribution and reproduction in particular requires that the authors and source are credited.

The license is subject to the Beilstein Journal of Organic Chemistry terms and conditions: (https://www.beilstein-journals.org/bjoc)

The definitive version of this article is the electronic one which can be found at: doi:10.3762/bjoc. 15.102 